IZA DP No. 4447

Could Education Promote the Israeli-Palestinian Peace Process?

Mayssun El-Attar

September 2009 


\title{
Could Education Promote the Israeli-Palestinian Peace Process?
}

\author{
Mayssun El-Attar \\ Centre for Microdata Methods and Practice (CeMMAP) \\ and IZA
}

Discussion Paper No. 4447

September 2009

\author{
IZA \\ P.O. Box 7240 \\ 53072 Bonn \\ Germany \\ Phone: +49-228-3894-0 \\ Fax: +49-228-3894-180 \\ E-mail: iza@iza.org
}

Any opinions expressed here are those of the author(s) and not those of IZA. Research published in this series may include views on policy, but the institute itself takes no institutional policy positions.

The Institute for the Study of Labor (IZA) in Bonn is a local and virtual international research center and a place of communication between science, politics and business. IZA is an independent nonprofit organization supported by Deutsche Post Foundation. The center is associated with the University of Bonn and offers a stimulating research environment through its international network, workshops and conferences, data service, project support, research visits and doctoral program. IZA engages in (i) original and internationally competitive research in all fields of labor economics, (ii) development of policy concepts, and (iii) dissemination of research results and concepts to the interested public.

IZA Discussion Papers often represent preliminary work and are circulated to encourage discussion. Citation of such a paper should account for its provisional character. A revised version may be available directly from the author. 


\section{ABSTRACT}

\section{Could Education Promote the Israeli-Palestinian Peace Process?*}

This paper explores Palestinians' attitudes towards a peace process and their determinants, with a particular focus on the role of education. Understanding the factors that shape attitudes towards peace is important in order to be successful in negotiations or in implementing a peace agreement. In the literature, there is particular disagreement about the role of education. While some authors have linked violent and extreme positions to ignorance and to low market opportunities, others have found that education is positively correlated with being a member of a terrorist group. To better understand the role of education I decompose the attitudes towards peace into two dimensions; attitudes towards reconciliation and attitudes towards concessions. To measure these attitudes, I use a flexible item response model proposed by Spady (2007), which allows to take into account the multidimensionality of the concepts. The results show that education has a positive effect on attitudes towards concessions but a negative effect on attitudes towards reconciliation. This may occur because relative to a situation of peace, highly educated individuals are more strongly affected by current depressed economic conditions in Palestine. They therefore have more to gain from a peace agreement and may thus be more willing to make concessions. At the same time, they may be more frustrated and therefore less willing to reconcile. I also find that their attitudes to reconciliation move closely with aggregate economic conditions, while those of less educated individual are also influenced by local factors such as the construction of the separation barrier in their region of residence.

JEL Classification: $\quad$ 120, O15, O53

Keywords: conflict resolution, education, latent attitudes, item response models

Corresponding author:

Mayssun El-Attar

Centre for Microdata Methods and Practice

Institute for Fiscal Studies

7 Ridgmount Street

London WC1E 7AE

United Kingdom

E-mail: mayssun_e@ifs.org.uk

\footnotetext{
* I would like to thank the Palestinian Center for Policy and Survey Research, especially Khalil Shikaki and Olfat S.Hammad for providing the data. I would also like to thank Richard Spady, Andrew Chesher, Luigi Guiso, Jerome Adda, Christian Dustmann, Markus Poschke, Konrad Smolinski, Rex Brynen, Sami Miaari and Carolina Villegas helpful comments and suggestions and Aida El-Attar for her work with the maps.
} 


\section{Introduction}

The Arab-Israeli conflict has been considered one of the most complex and emotion-laden historical problems of the twentieth century. This dispute between the State of Israel and the Palestinians living under Israeli occupation has played a critical role not only in Middle East politics, but also at the world level (see Freedman (1979)).

Repeatedly, a two state solution has been proposed, consisting in an independent Palestinian state next to the state of Israel. Several efforts at negotiating such a solution have taken place and failed. According to many polls, large majorities of Israelis and Palestinians would also favor a two state solution 11 Despite this basic agreement, there are significant areas of disagreement about what constitutes an acceptable solution. First, not all Palestinians and Israelis agree on the concessions they are willing to make in order to reach a peace agreement. Second, there is a problem of credibility; even if a peace agreement is reached, reconciliation between the two societies does not seem easy and therefore each side fears that the other might not keep the basic commitments. As a consequence, the conflict has been going on for many years and the level of violence has been increasing.

The goal of this paper is to analyze Palestinians' attitudes towards a peace process, with a particular focus on how these attitudes vary with personal and demographic characteristics. Attitudes matter. As Jaeger, Klor, Miaari and Paserman (2008) write, "These conflicts, [like the Israeli-Palestinian one,] in which a limited number of fatalities are used to affect negotiations, demoralize the civilian population, or strategically incapacitate the opponent, are largely psychological." Within Palestinian society, there are a variety of views and opinions. Understanding the factors that shape the attitudes of individual Palestinians is important because it can help to identify some important elements for a successful peace process. Recently, there have been some attempts to study the Israeli-Palestinian conflict from this point of view; e.g. Nachtwey and Tessler (2002), Jasso and Meyersson (2004), Friedman (2005) and Jaeger et al. (2008).

While exploring the determinants of Palestinians' attitudes to the conflict more generally,

\footnotetext{
${ }^{1}$ See results from surveys conducted by the Palestinian Survey Research for the Palestinians and Harry S. Truman Centre for the Israelis.
} 
this paper focusses in particular on the role played by education. Often, violent and extreme positions are attributed to ignorance and to low market opportunities. Berman and Laitin (2005) for instance use a 'club good' model to explain the function of voluntary religious organizations as providers of terrorism, where terrorism is seen as a local public good. A possible interpretation of this model is that poverty breeds terrorism as it lowers the outside options of club members. This link can also be found in the work by Bueno de Mesquita (2005), Bueno de Mesquita and Dickson (2007) and Jaeger et al. (2008). In contrast to this, Abadie (2006), Krueger and Maleckova (2003) and Berrebi (2007) find that suicide attackers and participants in violent groups tend to have higher education and living standards above the poverty line. Similarly, using a unique data set detailing the biographies of Palestinian suicide bombers, Benmelech and Berrebi (2007) estimate the returns to human capital in suicide bombing and find that older and more educated suicide bombers are assigned to more important targets and perform better (more casualties and lower probability of failure).

Because the relation between education and political violence is disputed, it is important to analyze its role for attitudes towards a peace process. In this, it is important to clearly distinguish income from education, and personal or family income from GDP per capita or the overall economic situation. While education may drive expected or potential income, this can be quite different from actual income. Indeed, given the currently very depressed returns to education Palestine (shown in Section 2.1), education conditional on current income is more likely a measure of an individual's current economic losses from the conflict. Therefore, education and income should not be expected to have similar effects.

For instance, as argued in Section 3 , if the earnings of educated individuals are more depressed relative to a situation of peace, then they may be more willing to make concessions to reach a peace agreement. At the same time, they may be more frustrated due to past losses and therefore less willing to reconcile. In contrast, it is not clear how current income conditional on education would evolve with a peace agreement; individuals may well all have similar expectations. Similarly, a change in the overall economic situation may affect attitudes differently from a change of an individual's situation relative to other Palestinians. One important contribution of the paper is to pay careful attention to these issues. 
The other main contribution of the paper lies in the measurement of the attitudes. I define attitudes towards a peace process as consisting of two components: attitudes towards 'chances for reconciliation and lasting peace in a scenario of successful negotiations' and attitudes 'on positions expressed and concessions discussed in the negotiations.' I develop a new measure of such attitudes, arguing that opinions of individuals about certain aspects of conflict resolution reflect their attitudes in these dimensions. Applying a new methodology by Spady (2007), I measure attitudes towards reconciliation and towards concessions as latent attitudes at the individual level. The data used is a series of item responses concerning attitudes towards reconciliation and towards concessions from some of the surveys realized by the Palestinian Center for Policy and Survey Research (PSR). This data is particularly useful because questions are very precise and allow distinguishing between attitudes towards reconciliation and towards concessions. I have information about attitudes towards reconciliation for the period 2001-2006 and about attitudes towards concessions for 2003-2006. Assuming that respondents' answers have been determined by their attitudes in these dimensions, the attitudes of individuals making up the sample population can then be given probability distributions, based on their item responses and personal characteristics. From these probability distributions I can infer the relation between individuals' economic and demographic characteristics and their attitudes.

The measure I propose allows for the multidimensionality of attitudes to peace (involving attitudes both towards reconciliation and towards concessions) and takes into account various facets of each of the dimensions. It thus goes beyond the use of a single, specific question, capturing only a single aspect of a particular dimension, as often seen in the literature (e.g. Jaeger et al. (2008)). This is important because a measure of a broad concept such as attitudes towards a peace process arguably improves if it can span several dimensions. In our analysis we use six items (questions) for the reconciliation scale and six for the concessions scale. Each of the items can be seen as reflecting a different dimension of the concept.

The results of the paper indicate that I) There are theoretical reasons for considering attitudes towards peace as composed of two distinct dimensions; attitudes towards reconciliation and attitudes towards concessions. This multidimensional construct provides new meaningful insights about the role of education. II) Education is positively related to attitudes towards 
concessions. III) In contrast to the results on concessions, education has a negative effect on attitudes towards reconciliation. This negative effect has been strengthening over the years in the sample (2001-2006). IV) What possibly drives the negative effect of education on attitudes towards reconciliation is a higher level of frustration for more educated individuals due to the low labor market opportunities. V) Attitudes towards reconciliation of individuals with high education closely follow the evolution of the overall economic situation. VI) Specific regional factors (construction of the Wall) influence attitudes towards reconciliation for individuals with low education only.

These findings also show that allowing for attitudes to peace to have more than one dimension is important for understanding the problems faced, as shown in particular by the different effect of education in different dimensions. Willingness to make concessions is a necessary condition to establish peace in a first stage. Reconciliation is also very important. Several authors (e.g. Kulle and Hamber (2000)) have emphasized that a lack of forgiveness may threaten the peace peace processes in the long run. Bar-Tal (2000) notices that there is not so much attention to the attitudes towards reconciliation. Reconciliation based on mutual trust and acceptance. In this paper we try to capture these several dimensions, for that, Spady's (2007) estimator has proven very useful.

The rest of the paper is structured as follows. Section 2 revises briefly the previous evidence on the relationship between individuals' attitudes and the conflict. Section 3 presents a simple theoretical argument for treating attitudes towards peace as a composite of two dimensions. This argument will also guide the estimation. In Section 4 I describe the methodology used to obtain the measure of the attitudes. In Section 5 I present the data used, and I describe the questionnaire items and the personal and demographic characteristics of the respondents that play a role in the estimation of the latent attitudes. In Section 6 I obtain the measure of attitudes towards concessions and towards reconciliation and analyze their determinants and their correlation with economic trends. I also investigate the channel through which the events of the conflict can shape attitudes. Finally, Section 7 concludes. 


\section{Previous evidence on the relationship between individuals' attitudes and the conflict}

The Israeli-Palestinian conflict has generated a considerable amount of social research. Most of this research implicitly assumes that the conflict shapes individuals' attitudes, and that these attitudes have an effect on individuals' behavior. Eckstein and Tsiddon (2004) for instance argue that in the presence of terrorist activity, individuals value the future less relative to the present. They show that these changes in individuals' preferences influence macroeconomic aggregates. Concretely, they lead to lower investment and lower income and consumption in the long run.

Zussman and Zussman (2006) evaluate the net effect of the Israeli counterterrorism policy on attitudes and on the economy. They argue that assassinating members of Palestinian terrorist organizations can be counterproductive if it increases Palestinians' motivation for future attacks. Their idea is that it is possible to find moral objections to this type of policy, and these moral objections can affect Palestinians' attitudes and therefore increase retaliation. To evaluate the

effect of this policy, they exploit the forward-looking and information-aggregating nature of asset markets. Using reactions of the Israeli stock market to news of counterterrorism operations, they find that assassinations of low-ranked members of Palestinian terrorist organizations are perceived as counterproductive. The opposite is true for assassinations of senior leaders.

Berrebi and Klor $(2006,2007)$ argue that terror attacks affect Israeli public opinion, which in turn has an effect on election outcomes. To study the relation between Palestinian militant groups and the Israeli political system they present a theoretical model where Palestinians commit terror attacks and Israelis elect governments. The model predicts that support for Israel's right-wing party increases after periods of severe terrorism, and that the expected level of terrorism is higher when a left-wing party is in power. They show empirical evidence that supports these results.

The work of Jaeger and Paserman (2006, 2007) focuses on trying to explain the dynamics of the violence. They find that Israel reacts in a predictable way to Palestinian attacks, while Palestinian actions do not appear to be related to Israeli violence. Their conclusion is that a cessation of Palestine violence against Israel may lead to an overall reduction in the level of violence. This result suggests that it is essential to understand the factors that shape Palestinians' 
attitudes towards peace and towards the resolution of the conflict.

However, Palestinians' attitudes have not been studied very much. Nachtwey and Tessler (2002) notice that "Only a small portion of this research [on the Palestinian-Israeli conflict] has explored the determinants of popular attitudes towards the conflict, however, the factors that shape Palestinian public opinion have been particularly neglected." They study the degree to which economic expectations change individuals' attitudes towards peace. Recently there have been some other attempts to study the conflict from this point of view. Jasso and Meyersson (2004) study the effects of identity and social distance on support for key provisions of the Roadmap, and Friedman (2005) studies the determinants of Palestinians' attitudes towards diplomacy and attacks. Similar to Nachtwey and Tessler (2002) they find that the economic impact of future peace exerts a positive effect but that individuals' current economic situation plays only a modest role. Jaeger et al. (2008) study how violence in the Second Intifada influences public opinion. They find evidence that Israeli violence against Palestinians temporary leads to more support for radical factions and to more radical attitudes towards the conflict.

An area where important advances are possible is the measurement of individuals' attitudes. Clearly, concepts like attitudes towards peace, towards reconciliation or towards violence are inherently difficult to measure. Using only one question (e.g. 'what party do you support?' or 'Do you think that lasting peace with Israel is possible?') is restrictive. It is difficult to believe that these partial measures are sufficient for capturing wider concepts like attitudes towards peace. The approach I use overcomes these limitations by incorporating more than one dimension of the attitudes towards peace, and by measuring each dimension using responses to more than one question.

Contentwise, an important question that this paper tackles concerns the link between attitudes and education. This issue is intimately linked to some important features of the Palestinian labor market.

\subsection{Labor market and returns to schooling}

The Palestinian economy is characterized by a labor market that is completely dependent on the Israeli market, and strongly influenced by political and social events. Palestinian unemployment and domestic wage respond to job opportunities and wages in Israel. Angrist (1995) analyzes 
the Palestinian labor market over the period 1981-1987 and finds that over that period, the unemployment rate of college graduates increased strongly, while returns to education declined substantially. The college premium fell from was $40 \%$ at the beginning of the period to $20 \%$ between 1984 and 1987. Angrist (1995) shows that changes in labor supply explain an important part of this development. The number of Palestinian college graduates increased sharply following the opening of Palestinian institutions of higher education, which had been totally absent before 1972 .

Sayre (2001a) studies the same period and stresses some demand factors that also explain part of the dramatic changes in returns to schooling. He argues that the reduction of demand for skilled Palestinian workers by the Arab Gulf countries, the increase in demand for unskilled Palestinian workers in Israel and changes in labor demand coming from changes in the volume of international trade can explain part of the changes observed during this period. Using a slightly different empirical approach, Sayre (2001b) finds that while supply changes could still account for most of the decrease in returns to schooling, demand shocks could explain as much as one-third of the change in the returns to a college. For similar reasons, the return to college remained low in the period 1995-2001 (Sayre and Miller 2004). Unemployment and wages in the Palestinian Territories continue to depend on the Israeli economy and are driven by closures, job permits, changes in the demand of low skilled workers, etc.

Angrist (1995) and Sayre (2001a) also link the bad labor market prospects for educated Palestinians from 1981 to 1988 to the uprising of the first Intifada. Sayre and Miller (2004) link the similar situation experienced by the Palestinian economy during 1995-2001 to the uprising of the second Intifada.

Although recently some papers have analyzed the effects of conflict and in particular border closures with Israel on the Palestinian economy and in particular the labor market (see Bulmer (2003), Miaari and Sauer (2006) or Maio and Nando) none of these studies report returns to schooling for the period under analysis in this paper (2001-2006). But economic conditions have worsened since 2000. Despite other factors that may affect the Palestinian economy, the World Bank (2003, 2004, 2005, 2007, 2008) repeatedly reported that the closures and restrictions on movements related to Israeli security concern have harmed the Palestinian economy and 
increased unemployment and poverty. Figure 1 shows rough estimates of the college premium in the Palestinian territories for the period under analysis. This figure shows that the college premium during this period has gone from $16 \%$ to $30 \%$. This is much lower than the college premium in the U.S., which is around $60 \%$ in this period (Goldin and Katz 2007).

This literature suggests that the depressed opportunities faced by highly educated Palestinians could shape their attitudes towards the peace process. The next section sets out a simple model showing which relationships we could expect.

\section{Education and willingness to make concessions and to recon- cile}

Suppose that Palestinians value consumption and derive value from their relationships with Israelis. These valuations govern their attitudes towards making concessions and towards reconciliation. Assume that the peace process has two stages. In a first stage, Palestinians and Israelis have to reach an official settlement or resolution and stop direct violence. Success depends on a negotiation process and on individuals' attitudes towards concessions on both sides. The second stage of the peace process consists in a normalization of the relationship between Palestinians and Israelis. This stage involves reconciliation and psycho/social healing. (these stages are also described in Gawerc (2006)).

Suppose that in the first stage of the conflict, Palestinians have the choice of how many

concessions to make. Denote the choice of concessions by $s \in \mathbb{R}_{0}^{+}$. Making concessions may lead to a peace agreement with Israel, with the probability $p$ of an agreement increasing in the amount of concessions made. However, the "marginal product" of concessions in increasing the probability of an agreement is decreasing and goes to zero in the limit $\left(p^{\prime}>0, p^{\prime \prime}<0\right.$, $\left.0 \leq p(0)<1, \lim _{s \rightarrow \infty} p(s) \leq 1\right)$. As a consequence, there is no finite amount of concessions that leads to an agreement with probability 1.

Individual Palestinians expect income of $w(e)$ after a peace agreement, which increases with the individual's education $e$. They currently earn $\bar{w}$. Reflecting the evidence discussed above, current income and returns to education are both depressed $\left(\bar{w}<w(e), \bar{w}^{\prime}(e)=0\right.$ for all $\left.e\right)$. For simplicity, current returns to education are set to zero. 
Whereas making concessions could raise future incomes, it also has a psychological (and possibly also a real) cost $c_{i}$ per unit of concessions. This differs across individuals. It may depend on demographics, but also vary in unobserved ways. While in principle, the cost could vary systematically with education, we abstract from this. Individuals then choose their optimal level of concessions by choosing $s$ to maximize the objective function $p(s) w(e)+(1-p(s)) \bar{w}-c_{i} s .^{2}$ The optimal $s$ is the theoretical counterpart to the willingness to concede we measure in the data. The optimal amount of concessions, if interior, then satisfies $p^{\prime}(s)[w(e)-\bar{w}]=c_{i}$. Because $p^{\prime}>0, p^{\prime \prime}<0, w^{\prime}>0$ and $w(e)>\bar{w}$, the optimal $s$ increases in education and decreases in the cost of concessions. More educated individuals have more to gain from concessions, so they are willing to invest more.

Palestinians also value the quality of the relationships they have with people around them. This includes Israelis, and this allows for an analysis of the willingness to reconcile. Reconciliation requires effort, but has benefits in terms of improving the quality of relationships, and possibly also has economic benefits. Denote these benefits by $R(r ; e)$, where $r$ denotes efforts to reconcile. The benefits depend on education because economic benefits of reconciliation are likely to vary with education. Assume that the marginal product of efforts at reconciliation, $R^{\prime}$, is positive but decreasing $\left(R^{\prime}(\cdot, e)>0, R^{\prime \prime}(\cdot, e)<0\right.$ for all $\left.e\right)$.

Engaging in reconciliation also has a psychological cost, as it may be hard to reconcile with people if past experience with them was bad. This cost increases in the level of frustration experienced due to the conflict. This psychological cost can be seen as hate generated because Palestinians see Israel as responsible for their miseries, roots of hatred in self-defense and vengeance. (Glaeser (2002) study the formation of hate). The experimental literature on reciprocity (see Fehr and Schmidt (2005)) confirms that subjects forgo rewards if that allows them to punish people who have behaved unfairly, particularly by rejecting unequal offers in ultimatum games. Concretely, as stated above, this hate and frustration may be linked to the poor labor market conditions and therefore may vary with individuals' level of education. Model this by assuming that the cost of reconciliation effort $c(e)$ increases in frustration due to the conflict, and that frustration is driven by the difference between potential and actual wages.

\footnotetext{
${ }^{2}$ If this was about actions, not attitudes, this would of course be a strategic game, where Israeli actions also matter for payoffs.
} 
Then $c(e)=f(w(e)-\bar{w}), f^{\prime}>0$ and $c^{\prime}(e)>0$. Individuals then set their optimal amount of reconciliation to maximize its benefits net of the psychological cost. This yields the optimality condition $R^{\prime}(r ; e)=c(e)$. Individuals engage in reconciliation up to the point where the marginal benefit equals the marginal cost. More educated individuals prefer a higher level of reconciliation if the benefits from it increase strongly enough with education. If benefits do not rise strongly with education, in contrast, more educated individuals prefer a lower level of reconciliation, as reconciliation is costly for them because of the frustration they have endured due to the depressed labor market conditions.

The link between attitudes towards reconciliation and the general economic losses such as the impact of the conflict on employment opportunities and returns to schooling has been suggested previously. Morrow 2000 argues that forgiveness and reconciliation in the context of ethnopolitical conflict could be considered an issue for society as a whole because personal injuries committed by the parties in conflict are often understood as the grief not only of individuals but of whole communities.

\section{Measuring individuals' attitudes}

\subsection{The Item Response Model}

In this section, I define a model for estimating the latent attitudes towards a peace process. The model used in this paper is a hierarchical item response mode $]^{3}$ estimated following the approach proposed by Spady (2007). The model is represented graphically in Figure 3.

From the considerations in the previous section, every individual has attitudes towards concessions and towards reconciliation that depend on the potential payoffs and costs they face. That is, the optimal $s$ implies an attitude towards concessions $A_{C}$ and the optimal $r$ an attitude towards reconciliation $A_{R}$. Together, these attitudes constitute the individual's predisposition towards a peace process. They also cause responses to survey questions on the issue. Finally, they also underlie agents' behavior; e.g. their political decisions or their propensity to engage in violence. The analysis of the impact of the attitudes on actions is left for future research.

From the model, education and other factors that systematically affect costs and payoffs

\footnotetext{
${ }^{3}$ See Steele and Goldstein (2007) for an overview of this type of item response models.
} 
affect the willingness to make concessions and the willingness to reconcile. Solving the optimality conditions for the optimal choices then leads to the empirical specification

$$
\begin{aligned}
& A_{C}=h_{C}\left(e, X, \epsilon_{C}\right) \\
& A_{R}=h_{R}\left(e, X, \epsilon_{R}\right)
\end{aligned}
$$

where $X$ is a vector of covariates that captures differences in individuals' costs or preferences. The empirical specification thus reflects the idea that individual characteristics and experiences as well as community characteristics can be related to individuals' attitudes towards reconciliation and towards concessions. It is also assumed that these characteristics do not affect the answers directly, but only through their effect on the attitudes.

Equations (1) and (2) constitute a structural model with the following underlying assumptions: (1) the expressions of agreement and disagreement on questions about conflict resolution ('item responses') reflect corresponding attitudes of the responder; (2) the 'attitudes' are enduring individual-specific attributes, given the individual's characteristics and environment; and (3) each one of the series of item responses used is determined by a single attitude only (attitudes towards reconciliation and attitudes towards concessions respectively).

The variables used to estimate the individual attitudes and those included in $X$ are discussed in Section 5. Before that, I describe how to obtain the likelihood function used to measure the attitudes towards reconciliation and to obtain the correlates with the individual personal characteristics. The likelihood function and the estimation method used for the analysis of the attitudes towards concessions is the same. It only differs in the use of different questions. I denote the items used to construct the reconciliation scale as $R$ and the items used to construct the concessions scale as $C$.

\subsection{Structural Representation}

Consider a system of $M$ measurements $R_{m},(m=1 \ldots M)$ for a latent factor $A$ :

$$
\begin{gathered}
R_{1}=g_{1}\left(A, U_{1}\right) \\
\vdots \\
R_{M}=g_{M}\left(A, U_{M}\right)
\end{gathered}
$$


where $A$ is univariate, $U_{m} \sim U(0,1)$ and $g_{m}(\cdot)$ is weakly increasing in $U$ and strictly increasing in $A$. It is also assumed that $U_{i} \perp U_{j} \forall i \neq j$ and $U_{i} \perp A \forall i$ which implies that conditional on $A$ the responses are independent $\left(R_{i} \perp R_{j} \mid A\right) 4^{4}$

Personal characteristics may affect the way this latent variable is distributed in the population. We assume that individual characteristics, and particularly education, may affect the latent variable $A$, but do not affect the measurements $R_{m}$ directly. (They can of course affect them via $A$.) Consider the linear case

$$
A=h(X, \epsilon)=X \beta+\varepsilon
$$

where $\varepsilon \sim N(0,1)$ and $\varepsilon \perp X$. Assume also that $U_{m} \perp \varepsilon$ and $U_{m} \perp X$.

Denoting a realization of $A$ by $a$, consider the following threshold representation for a given response variable:

$$
g_{m}\left(a, u_{m}\right)= \begin{cases}1 & \text { if } Q_{0}(a)<u_{m} \leq Q_{1}(a) \\ 2 & \text { if } Q_{1}(a)<u_{m} \leq Q_{2}(a) \\ 3 & \text { if } Q_{2}(a)<u_{m} \leq Q_{3}(a) \\ 4 & \text { if } Q_{3}(a)<u_{m} \leq Q_{4}(a)\end{cases}
$$

where $Q_{r}(a), r=\{1,2,3,4\}$, are thresholds functions for item $m$, and $0=Q_{0}(a)<Q_{1}(a)<$ $Q_{2}(a)<Q_{3}(a)<Q_{4}(a)=1$. Figure 2 shows the graphical representation of the functions $Q_{r}(a)$. This figure shows that higher item responses are associated to higher values of $a$, i.e. if $a_{2}>a_{1}$ then the item responses of $a_{2}$ population stochastically dominate $a_{1}$. Thus, higher item responses are associated to higher values of $a$. This assumption implies that the lines that indicate the probability of answering $k$ or higher in item $j$ given $a$ have to be downward sloping. Of course, they cannot cross if probabilities are to be non-negative.

The model is identified if the structure, together with the restrictions of the model, delivers the distribution of observables:

$$
S=\left\{g(A, U), F_{U \mid A}\right\} \Rightarrow F_{R \mid A},
$$

where $F_{U \mid A}$ denotes the cumulative distribution function of a random variable $U$ conditional on

\footnotetext{
${ }^{4}$ These assumptions correspond to the standard assumption in item response theory (IRT); unidimensionality ( $A$ is unidimensional), monotonicity $\left(g_{m}\left(A, U_{m}\right)\right.$ is strictly increasing in $\left.A\right)$ and local independence. See Steele and Goldstein (2007) for a review of hierarchical parametric IRT.
} 
$A$. From the identification result, the following equality follows:

$$
F_{U \mid A}\left(Q_{r}(a) \mid A=a\right)=F_{R \mid A}(r \mid A=a)
$$

and because of the uniformity of the error term

$$
Q_{r}(a)=F_{R \mid A}(r \mid A=a)=\operatorname{Pr}(R \leq r \mid A=a) .
$$

$Q_{r}(a)$ thus is a conditional cumulative distribution function.

The way of modeling $\operatorname{Pr}(R \leq r \mid A=a)$ differs among different types of item response models. In this paper these functions are modeled as in Spady (2007), using the distribution function corresponding to an exponential tilting of second degree of the uniform density,

$$
G_{r}(a)=\frac{\int_{0}^{a} e^{\tau_{1} \gamma_{1}(u)+\tau_{2} \gamma_{2}(u)} d u}{\int_{0}^{1} e^{\tau_{1} \gamma_{1}(u)+\tau_{2} \gamma_{2}(u)} d u}
$$

where the functions $\gamma_{1}(u)$ and $\gamma_{2}(u)$ are 2 basis functions, chosen to be (shifted) Legendre polynomials and $\tau_{1}$ and $\tau_{2}$ are the parameters estimated. From $G_{r}(a)$ we obtain $Q_{r}(a)$ as $Q_{r}(a)=1-G_{r}(a)$.

To ensure that the lines do not cross, they are constructed as products of the estimated distribution functions. Consider an item $m$ with 4 possible answers, so $r=\{1,2,3,4\}, Q_{4}(a)=$ 1 and $Q_{0}(a)=0$ by definition. Assume $Q_{3}(a), G_{2}(a)$ and $G_{1}(a)$ are distribution functions estimated as described above. Then $Q_{2}(a)=\left[1-G_{2}(a)\right] Q_{3}(a)$ and $Q_{1}(a)=\left[1-G_{1}(a)\right] Q_{2}(a) .5$

To build the likelihood function, the conditional probability of a response $r, \operatorname{Pr}(R=r \mid A=$ a), is obtained as

$$
\begin{aligned}
\operatorname{Pr}(R=r \mid A=a) & =\operatorname{Pr}(R \leq r \mid A=a)-\operatorname{Pr}(R \leq r-1 \mid A=a) \\
& =Q_{r}(a)-Q_{r-1}(a)
\end{aligned}
$$

To simplify notation, denote $\operatorname{Pr}(R=r \mid A=a)$ as $p\left(r \mid a ; \tau_{r}\right)$.

The likelihood function for $N$ independent observations then is

$$
\begin{aligned}
p\left(r_{1}, r_{2}, \ldots, r_{M} \mid X ; \beta, \tau\right) & =\prod_{n=1}^{N} \int p\left(r_{1}, r_{2}, \ldots, r_{M} \mid a, \tau_{m, r}\right) f(a \mid X ; \beta) d a \\
& =\prod_{n=1}^{N} \int p\left(r_{1} \mid a ; \tau_{1, r}\right) p\left(r_{2} \mid a ; \tau_{2, r}\right) \ldots p\left(r_{M} \mid a ; \tau_{M, r}\right) f(a \mid X ; \beta) d a .
\end{aligned}
$$

\footnotetext{
${ }^{5}$ This also implies that the stochastic dominance is strengthened to dominance in hazard order.
} 
Because of the assumption of conditional independence of the responses, it is possible to express the likelihood function as a product of the conditional item probabilities. $\beta$ is a vector of parameters that indicates the effect of $X$ on the mean of $A . \tau$ parameterizes the distribution $Q_{r}\left(a ; \tau_{m, r}\right)$ that enters $p(\cdot)$. With two-parameter exponential tilting, it consists of elements $\tau_{m, r}=\left(\tau_{m, r}^{1}, \tau_{m, r}^{2}\right)$.

The integral in the likelihood function has no general closed form solution. The integration is thus carried out using Gauss-Hermite quadrature at 200 grid points. Quadrature methods approximate the integral as a weighted sum of function values evaluated over a grid of points so that

$$
\int f(x) d x \approx \sum_{q} w_{q} f\left(x_{q}\right)
$$

Gaussian quadrature rules choose not only the weights, but also the evaluation points or abcissæ, and can achieve higher precision with a fix number of points. To ensure that we can take into account even distributions with small variance, Gaussian quadrature has been applied to 5 different segments of the grid, with the segment in the middle having a higher concentration of points. A Newton-Raphson algorithm is used to maximize the log-likelihood function. Concretely, we use the BFGS method which builds an approximation to the Hessian in the course of iteration 6

\subsection{Identification}

The model is defined as the structure

$$
S=\left\{g(A, U), F_{U \mid A}\right\}
$$

with

$$
F_{U \mid A}\left(Q_{r}(a) \mid A=a\right)=F_{R \mid A}(r \mid A=a)
$$

and the restrictions described above: $U_{m} \sim U(0,1), g_{m}(\cdot)$ is weakly increasing in $U$ and strictly increasing in $A, U_{i} \perp A \forall i, U_{i} \perp U_{j} \forall i \neq j, f(a)$ is assumed to be known. The model identifies

\footnotetext{
${ }^{6}$ For a general discussion about estimation procedures for multilevel generalized linear models see Rodriguez (2008).
} 
$g_{m}(\cdot)$ if $\forall\left(S^{*}, S^{0}\right), S^{*} \neq S^{0}$,

$$
\begin{aligned}
& F_{U \mid A}^{*}\left(Q_{r}^{*}(a) \mid A=a\right)=F_{R \mid A}^{*}(r \mid A=a) \\
& F_{U \mid A}^{0}\left(Q_{r}^{0}(a) \mid A=a\right)=F_{R \mid A}^{0}(r \mid A=a)
\end{aligned}
$$

and $F_{R \mid A}^{*}(r \mid A=a) \neq F_{R \mid A}^{0}(r \mid A=a)$.

To ensure that the model uniquely identifies $F(R \mid A=a)$, it is necessary to impose parametric restrictions. Hu and Schennach (2006) have a nonlinear measurement error model that is related to the model presented here. These authors relate the joint densities of the observable variables to the joint densities of the unobservable variables in the same way as equation 6 shows. This equation admits an equivalent operator representation:

$$
L_{R \mid X}=L_{R \mid A} L_{A \mid X}
$$

The proof of identification relies on the assumption of the operator $L_{R \mid A} \equiv \int f_{R \mid A}(R \mid A=$ a) $g(A)$ A being 'injective'. Intuitively, $L_{R \mid A}$ will be injective if there is enough variation in the density of $R$ for different values of $A$ (or $X$ ). In our case this assumption is not fulfilled because of the discreteness of $R$ combined with finite amount of data. Therefore, the proof that $\mathrm{Hu}$ and Schennach (2006) propose is not be applicable in our case.

Douglas (2001) shows that nonparametric item response models are only identifiable in an asymptotic sense, i.e., when the number of items tends to infinity, in which case the problem would be the one analyzed by $\mathrm{Hu}$ and Schennach (2006). For parametric models identification reduces to showing that the number of constraints of the form:

$$
p\left(r_{1}, r_{2}, \ldots, r_{M}\right)=\int p\left(r_{1}, r_{2}, \ldots, r_{M} \mid a, \tau_{m, r}\right) f(a) d a
$$

generated by the different combinations of responses limits the values of the parameters to a unique set. If $Q_{r}(a)$ were modeled nonparametrically, the degrees of freedom would be much greater than the number of constraints, considering that the value of the function at each point may be viewed as a separate parameter and the constraints derived from the manifest distributions are not sufficient to identify $Q_{r}(a)$. The set up of this paper is parametric; $Q_{r}(a ; \tau)$ is modeled as a function of some parameters. 
There are $4^{6}-1=4094$ possible constraints in the model of attitudes towards reconciliation and $3^{7}-1=2186$ in the model of attitudes towards concessions. Since there are many constraints/points of support, the estimation of $Q_{r}(a ; \tau)$, although parametric, is very flexible. The set up of this paper approximates these distributions using two parameters, therefore the degrees of freedom are larger than the parameters to be estimated, the model identifies the functions $g_{m}(\cdot)$.

Also close to our model is the measurement error model analyzed in $\mathrm{Hu}$ (2008), where the variable with measurement error and the misclassified measurements are assumed to be discrete. In that case, the author shows that the latent model can be expressed as an explicit function of directly observed distribution functions and that therefore, under this framework $f_{R \mid A}$ and $f_{A \mid X}$ are nonparametric identified.

In this paper we have considered that since the points of support are large enough, this allows us to model the latent variables as continuous and still obtain a sufficient flexible approximation of $Q_{r}(a ; \tau)$.

\section{Data}

The data comes from the public opinion surveys designed and conducted by the Palestinian Center for Policy and Survey Research (PCPSR). This institution conducted public opinion polls from 2000 to 2008, collecting information about attitudes and values of a representative sample of Palestinians in the West Bank and the Gaza Strip, including East Jerusalem. The surveys used in this paper are the ones that include exactly the same questions about attitudes towards reconciliation: December 2001 (poll \#3), May 2002 (poll \#4), April 2003 (poll \#7), March 2005 (poll \#15) and December 2006 (poll \#22). These surveys also include information about personal and demographic characteristics. To measure attitudes towards concession I use data for December 2003 (poll \#10), December 2005 (poll \#18), and December 2006 (poll \#22). The only survey that contains information on both concessions and reconciliation is the one for December 2006.

This data set is particularly useful because questions are very precise and allow distinguishing between attitudes towards reconciliation and towards concessions. The items reflecting attitudes 
towards reconciliation emphasize that the questions refer to steps that the Palestinians could take once the state of Palestine was established. The items reflecting attitudes towards concessions refer to key issues such as final borders, the status of Jerusalem, refugees, and the security arrangements that have been recurrently brought up during peace negotiations (the Geneva Initiative, the Clinton Parameters and the Taba Negotiations). This distinction is important because the use of more general questions can lead to misleading conclusions. For instance, measuring attitudes towards peace using the support for the continuation of peace negotiations as in Abu Sada (1998) is problematic because individuals' answers are also affected by other factors like their confidence in the leaders involved in the negotiations. The use of party identification as a way to infer attitudes, as used for example in Jaeger et al. (2008), can also lead to wrong conclusions since other issues like a person's degree of religiosity or the current ruling party's level of corruption can play a role. Hence, the precise wording of the questions in the survey used here makes more precise measurement possible and makes the data set particularly useful. The full wording of the questions/items used to estimate the individuals' latent attitudes is shown in the appendix.

Summary statistics of the responses to these items are presented in Table 1 . Items on reconciliation have four possible answers (scale from 1 to 4 ) and items on concessions have three possible answers (scale from 1 to 3 ). A higher score corresponds to a more positive attitude towards reconciliation or concessions. Even among the items referring to one attitude, answering behavior varies over these items. Considering for instance the question "Would you support to adopt a school curriculum in the Palestinian state that recognizes Israel and teaches school children not to demand the return of all Palestine to the Palestinians?" and the question "In case of a two state solution, would you support to open borders to free movement of people and goods?", the mean answer differs strongly, at 1.71 for the first question and 3.04 for the second. This indicates that different items carry information on respondents' attitudes to a varying degree, or capture different aspects. Thus, by focussing on just one questions, or on a narrow subset of questions, valuable information may be lost. This is also indicated by the pairwise correlation coefficients for the items shown in Table 2; correlations are positive but far from perfect. 
The theoretical model suggests that some demographic variables are informative about the individual attitudes. Therefore, they are also used in the estimation. A descriptive analysis of these variables is shown in Table 3 . This table shows an increase in the percentage of individuals with high levels of education and with a high degree of religiosity. The theoretical justification for the inclusion of personal and demographics characteristics in the estimation is the following:

Education. As seen above, the role of education in shaping attitudes towards a peace process is not well understood in the existing literature. The goal of this paper is to shed some light on the connection of education with Palestinians' attitudes. To measure education I use three dummy variables: Low education (elementary education or less), medium education (preparatory or secondary education) and and high education (college or more).

Religion: personal piety. Tessler and Nachtway (1998) state that "the theoretical linkage between religion and international politics is based on the assumption that religion plays a crucial role in shaping both the normative orientation of individuals and their understanding of the surrounding world." They find that different dimensions of religiosity have different effects on individuals' attitudes towards politics or towards international conflicts. They find that support for political Islam and religious activism have a strong effect on an individual's political views, while personal piety is unrelated to those views. Unfortunately, I am not able to distinguish between these two dimensions of religiosity. The surveys only contain information on the degree of personal piety. The measure of personal piety used are three dummy variables based on the answer to the following question: "How often do you pray? 1) every day, 2) only on Friday or occasionally, 3) rarely or never."

Economic determinants: household income/family size. The relation between individuals' current economic situation and their attitudes is a priori ambiguous. It could be that individuals who are currently doing well believe that this will allow them to benefit more from economic opportunities arising with peace. It may, however, also motivate them to avoid change, and pit them against an agreement, whereas the poor might support it in the hope of an improvement in their situation, and because they have little to lose. On the other hand, they may 
be frustrated due to their economic situation, and not believe in the benefits of an agreement. In this sense, Nachtwey and Tessler (2002) find that currently unsatisfied individuals tend to be against an agreement. In addition, there is some new evidence finding little relationship between hate crimes in general and economic conditions.7 It is possible that this relationship (or its absence) also holds for attitudes towards reconciliation.

We measure household income using three dummies: Low Income (monthly income per person in the household $\leq 125 \$$ ), medium income (income per person between 125 and $450 \$$ ) and high income (income per person $>450 \$$ ).

Age. Since attitudes might change over the life cycle due to personal experience but also due to national and global developments, the age of respondents can be informative 8

Working for the Public Sector. The public sector continues to be an important source of employment in Palestine. In 2003, public sector employment (by the Palestinian Authorithy and by municipalities) accounted for an estimated 26 percent of total employment in the West Bank and Gaza. For many young men coming from poor families this is the only route of social mobility. Therefore, working for the public sector is also an indication of how well the individual is doing. In addition, working in the public sector may of course by itself influence attitudes.

Being unmarried. Being unmarried in Palestine can be a source of frustration. Marriage is important because in Palestine, it represents the key to adulthood. It also is a religious obligation. Marriage is expensive; some families have to save all their lives to afford the wedding of their children 9 Since the economic situation has been deteriorating in the last years, it is possible that individuals who cannot afford marriage seek outlets for their frustration, translating into more negative attitudes towards reconciliation.

We also control for gender and region of residence as they can influence the experiences faced during life.

\footnotetext{
${ }^{7}$ See Krueger and Maleckova (2003). Green, McFalls and Smith (2001) provide a survey of the literature on hate crimes.

${ }^{8}$ Note that the variable used is age standardized by its mean, and standardized age squared over 100.

${ }^{9}$ For an illustration, see 'The wedding shortage', Navtej Dhillon, Newsweek.com, March 2007. This article explains why the Middle East has the lowest rates of marriage in the developing world.
} 


\section{Results}

In this section I use the methodology explained above to infer the relationship between demographics and attitudes towards concessions and towards reconciliation. I then use the construction of the separation barrier to explore the channel through which the conflict affects attitudes towards reconciliation differently across education groups.

\subsection{Attitudes towards concessions}

Table 4 shows the effect of the personal characteristics on the mean of the probability distribution of attitudes towards concessions for a given person. They correspond to the coefficient vector $\beta$ in equation (3). The effects are additive, which means that statements such as 'more educated people have more positive attitudes towards concessions' must be understood in a 'ceteris paribus' sense (Spady 2006). Coefficients describe deviations from a 'standardized' person. This is a male who lives in Hebron, has the mean age of the sample, is married, has a medium level of income per family member, is not a refugee, has low education and prays very often.

Results show that education is positively related to attitudes towards concessions. This finding is in line with the argument advanced above that more educated people could have more to gain from an agreement that eases the constraints on the Palestinian economy and therefore have more to gain from concessions.

Family income also matters; families with lower income tend to support the concessions discussed in the peace talks. Again, controlling for education, these might be the ones who have most to gain (or least to lose) from an agreement. The degree of religiosity reduces the willingness to make concessions.

Other authors have found that education has a negative impact on attitudes towards continuing with the peace negotiations after the Oslo agreements (Abu Sada 1998) or towards the Road Map (Jasso and Meyersson 2004). These authors explain this result by the fact that better educated respondents have more access to information and are therefore more aware of the problems of the possible agreements. Because of the different questions used to measure the attitudes, it is difficult to compare their results with the ones in this paper. The questions used in those papers are related to a particular moment in time and to a particular negotiation process. 
It seems likely that the individuals' answers take into account other factors like the strength of the Palestinian leaders or the international and Israeli political situation. The questions used in this paper to measure attitudes towards concessions are more atemporal in the sense that they are related to the key elements that have recurrently been subject of negotiation in peace talks. Therefore they provide more reliable information on individuals' general attitudes towards concessions.

\subsection{Education and attitudes towards reconciliation}

The previous section described results about willingness to make concessions obtained using a collection of items $C_{m}$. In this section I measure 'attitudes towards reconciliation' using a different collection of items $R_{m}$.

Results are presented in Table 5. It is clear that they differ substantially from those for concessions. In particular, education is negatively correlated with attitudes towards reconciliation. This negative effect has strengthened over the years in the sample (2001-2006). Figure 5 shows the evolution of the effect of education over time. The coefficient on the high education dummy is significantly negative in all years except for 2001, and becomes stronger (more negative) over time. The coefficient on the medium education dummy is less negative, but evolves very much in parallel with the high education coefficient. (The omitted group is low education.)

These results lend support to the idea that the depressed market opportunities of highly educated workers and the frustration generated by the difference between expected and actual wages matter for attitudes towards reconciliation (assuming that Palestinians attribute this lack of opportunities to the conflict and the interdependence with Israel). This hypothesis also fits with the strengthening of the education coefficient that accompanies the deterioration of the political and economic situation over the sample.

Reconciliation, economic expectations, and political events: It is instructive to consider the evolution of attitudes over time in more detail. Figure 5 plots the coefficients associated to the high and medium education variables obtained from the different samples together with the evolution of GDP per capita. From visual inspection, it is clear that attitudes of the highly educated individuals and GDP per capita move together closely over time. 
In particular, the fall in GDP per capita from the beginning of the second Intifada in 2000 until 2002 is accompanied by a steep drop in the attitudes towards reconciliation of the highly educated. Afterwards, as GDP per capita recovers following the Road Map conference, attitudes also improve again briefly, only to deteriorate again from 2003 onwards. They reach a low point in 2006, the year Hamas wins the Parliamentary elections. The international response to that victory again caused an important drop in GDP per capita. Overall, since the start of the Second Intifada in 2000, per capita GDP in Palestine has fallen by about a third, from $\$ 1621$ in 1999 to $\$ 1129$ by the end of 2006 . Attitudes of the highly educated have evolved in a similar way. More formally, the correlation between the coefficients on the education variables for the different years and GDP per capita or economic growth is positive and in almost all the cases statistically significant (see Table 6).

Because the evolution of GDP is closely linked to political events (the Intifada, peace talks), it is not clear whether the close link between GDP and attitudes of the educated is due to the evolution of GDP or whether politics is a common driving force. There is also the third possibility of attitudes driving some political events. All this indicates that there is a strong interdependence between politics and economics in the West Bank and Gaza, and that there is an interdependence between the socio-economic situation and attitudes towards reconciliation.

Although economic factors are often mentioned and may matter at the aggregate level, we find that family income does not have a significant effect on attitudes towards reconciliation. So relative income (conditional on education) is not significantly related to these attitudes. This suggests that it is overall and not individual economic deprivation that is closely related to attitudes.

These results are similar to results obtained in the literature on education and violence. For instance, Krueger and Maleckova (2003) and Berrebi (2007) both find that "having a living standard above the poverty line or a secondary school or higher education is positively associated with participation in violent groups." Although our explanation relates low willingness to reconcile to the lack of opportunities in the labor market, the results are also consistent with the hypothesis stated by these authors that more highly educated individuals have a more acute awareness of the political situation, resulting in deeper moral concerns and a more negative at- 
titude towards reconciliation. This hypothesis fits well with the strengthening of the education coefficient that accompanies the deteriorating political and economic situation.

Finally, both Krueger and Maleckova (2003) and Berrebi (2007) point out the possibility that the positive relationship between education and violence could be related to the content of the education. For instance, Stern (2000) explains how religious schools in Pakistan can induce students to get involved in violence and terrorism. In the case of Palestine it is unlikely that the education system itself negatively affects attitudes to reconciliation. In 2006 around 67 percent of students were enrolled in Palestinian Authority public schools, 27.2 percent in schools run by the United Nations (UNRWA), and 6.2 percent in private or NGO-run schools, including those linked to Hamas and other groups ${ }^{10}$ Figure 4 shows the evolution of the distribution of schools of each type during 2001 to 2007 . The share of private schools is small and stable over the period. So even if religious schools gained importance among private schools, this can only be a minor phenomenon. Although it is true that the curriculum of Palestinian public schools has been criticized for containing anti-Semitic stereotypes, this refers to primary and secondary schools only 11 Therefore, if the content of education was radicalizing students, it should have an effect on the whole sample. It is implausible that it mainly affects the most highly educated individuals.

Another factor that is strongly related to attitudes towards reconciliation is the degree of religiosity (measured as the frequency with which the individual prays). The results indicate that in 2001, the attitudinal differences between individuals with different degree of religiosity were weak. With time, differences become more clear. More religious people tend be less favorable to reconciliation. Causality is not clear, since we do not know if people with more negative attitudes towards reconciliation become more religious or if more religious individuals changed their attitudes toward reconciliation.

Being female, being a refugee, working for the public sector, or being unmarried do not have significant effects. The influence of age is not clear.

Overall, educated or religious individuals are less in favor of reconciliation with Israel, with

\footnotetext{
${ }^{10}$ Source: 'Factbox - Facts about Palestinian schools,' Reuters Foundation, September 2006.

${ }^{11}$ This has led to the introduction of new textbooks in 2000 , but the sample of individuals under analysis has not been affected by this. For more information on the old and new textbooks see Brown (2001).
} 
the effects of education and religion strengthening over time. In the next section, we have a closer look at the effect of education.

\subsection{The effect of the separation barrier on attitudes towards reconciliation}

In the previous sections I have linked the negative effect of education to the frustration derived from the general economic losses such as the impact of the conflict on employment opportunities

and returns to schooling. In this section I will give more evidence in line with the idea that are events at the national, not local level matter for attitudes. For this, I exploit the construction of the separation wall and regional fatalities.

In June 2002 the Israeli authorities began building a barrier (wall) along the border of the West Bank with Israel. The Israeli government has declared that the objective of the wall is to protect Israeli citizens from the attacks of suicide bombers. The trajectory of the wall is depicted in Figure 6. The first parts were built in the northern West Bank districts of Jenin, Tulkarem and Qalqilia. At the end of July 2003 Israel also started building a wall in the northern and eastern parts of Jerusalem and Bethlehem. After that, the wall continued south to Hebron. To build the wall, Palestinian land has been expropriated. In addition, the wall at times extends far into the West Bank, leaving parts of it inaccessible or disrupting circulation between villages.

The effects of the separation barrier on the Palestinians is twofold. Firstly, it affects Palestinians who live nearby, particularly their ability to travel freely within the West Bank and to access work in Israel, or to access other services (health, education or religious sites). Its presence also reduces arable land. Therefore the separation barrier directly affects the population of the localities through which the wall passes, resulting in localized economic losses. Secondly, many Palestinians see the separation barrier as an attempt to artificially create a border, creating 'facts on the ground.' Therefore, the wall can also affect Palestinians generally, not only locally, causing moral and existential concerns.

The construction of the wall helps to explore the channel through which education affects attitudes towards reconciliation. Controlling for the disruption caused by the construction of the wall in an individual's region of residence allows to capture the local effect of the wall. This can be done separately by group of education, giving an indication of how the experience of personal losses shapes attitudes for different groups of education. Any additional effect of education on 
attitudes should then be due to other, more general concerns.

This analysis is possible because the data indicate in which region individuals live. In addition, I use measures of the evolution of the length of the wall, the areas of land left on the Israeli side of the wall (in most of the cases, this land has been confiscated) and the areas that have become enclaves 12

I have this information for July 2003, February 2005, and July 2006. The first two dates correspond quite closely to the moments in time when the surveys have been conducted (maximum difference of three months). For 2006, the difference is larger. To deal with this, I assume that the parts of the wall that were under construction in July 2006 were completed by the time of the survey, in December 2006. To construct the measures of the effect of the wall, I use the following index:

$$
W E_{R}=\frac{\text { Wall }_{R}}{\text { Border }_{R}}+\frac{\text { OutsideLand }_{R}+\text { Enclaves }_{R}}{\text { TotalArea }_{R}}
$$

where $W E_{R}$ refers to the effect of the wall in region $R, W a l_{R}$ is the length of the wall expressed in $k m$, and $\operatorname{Border}_{R}$ refers to the length of the Green Line border for region $R$ expressed in $\mathrm{km}$. The OutsideLand is the area of the region that remains between the Green Line and the wall and the Enclaves $_{R}$ are the areas that have become enclaves due to the route of the wall. These areas are divided by the total area of the region and they are all expressed in $\mathrm{km}^{2}$. Figure 6 and tables 7,8 and 9 show the evolution of the construction of the wall and the measures used to construct the index. While it is not obvious if the functional form chosen is optimal for fitting disruptions suffered by individuals living in adjacent regions, it receives some support from evidence suggesting that other possible measures of the effect of the wall are correlated with the index constructed here. Using data for 2005, figure 7 shows the relation of $W E_{R}$ for 2005 with the number of buildings destroyed and with the amount of land that has been expropriated. The correlation between $W E_{R}$ and the two alternative measures is 0.61 and 0.57 respectively 13

With this measure I can then test whether living close to the wall and being exposed to its effects affects attitudes. Because the effect of the wall differs across regions and over time, it can be distinguished from just a year effect and from regional effects. In addition, because deviations

\footnotetext{
${ }^{12}$ Sources: These measures have been computed with information from the U.N. Office for the Coordination of Humanitarian Affairs in the Occupied Palestinian Territory and the Palestinian Environmental NGO's network.

${ }^{13}$ Note that it was not possible to directly use these alternative measure in our analysis since they are available only for 2005. Moreover, they are not available for the region of Toubas.
} 
of the wall from the Green Line are mainly guided by the placement of Israeli settlements and by the location of natural resources, the index is exogenous 14

Results are reported in table 10. The first column shows results for the whole sample. It confirms the effects found above; more educated or more religious people are less in favor of reconciliation. In addition, we find that living in areas strongly affected by the wall does not make people less favorable to reconciliation. Although negative, the coefficient is statistically significant only at a $15 \%$ level. Splitting the sample by education (low and medium levels of education vs high levels of education) produces interesting results. While other signs and levels of significance are largely unchanged, effects of living close to the wall are smaller and less significant for people with high levels of education.

The result that personal losses due to the wall have a weaker effect on attitudes of people with higher education may arise for several reasons. One possibility is that the wall must be affecting certain occupations more than others. Low educated individuals are more likely to be farmers, a group particularly strongly affected by the wall, both because of the loss of arable land and because of the disruption of transport routes 15

Overall, education is negatively related to attitudes towards reconciliation, in contrast to the effect found for personal losses. The presence of the wall thus cannot be the driving force behind the negative effect of education. More educated people seem to react to something else. The evolution of the education coefficient over time suggests that a more acute perception of the political and socioeconomic situation could be driving their attitudes towards reconciliation with Israel.

\footnotetext{
${ }^{14}$ The Government of Israel maintains that the following considerations are taken into account when determining the route of the wall: continuity in order to be operational, creation of controlled areas, minimum damage to the landscape, avoidance of the inclusion of Palestinian villages in the areas of the security fence, and minimal disruption in the daily life of the population residing near the wall. See the Israeli Ministry of Defense's website: www.seamzone.mod.gov.il. Concerning the settlements, Ariel Sharon's cabinet agreed to extend the wall to encircle Jewish settlements deep in the West Bank (see 'Israeli cabinet extends 'security fence", The Guardian, October 2 2003). The International Court of Justice Report of 8 September 2003 (E/CN.4/2004/6) also points out that the Wall incorporates illegal Israeli settlements that form the subject of negotiations between Israel and Palestine.

${ }^{15}$ See B'Tselem report on the effects of the wall. B'Tselem is the information center for human rights in the occupied territories.
} 


\section{Conclusion}

Given the importance of the Israeli-Palestinian conflict, hints about why it is so hard to resolve are very valuable. In this paper, I have used Palestinian survey data to explore the determinants of Palestinians' attitudes towards the peace process, understood as attitudes towards possible concessions they might be willing to make to achieve a settlement, and attitudes towards reconciliation in case of such a settlement. Because of the breadth of the object to be measured, the use of more than one dimension is natural. This is confirmed by the empirical analysis of the joint distribution of attitudes. Concerning the determinants, we focus particularly on education because of its ambiguous role in previous literature.

On economic grounds, more educated people could be expected to have more to gain from a peace process, in particular in the context of the repressed Palestinian economy. The empirical analysis indeed confirms that controlling for current family income more educated people are more willing to make concessions. This could be understood as an investment in peace, allowing the dividends of peace to be reaped later on.

The effect of education on attitudes towards reconciliation is disputed in previous work. Some authors argue that less educated people are more prone to violence and hatred, while others find the opposite: more educated people are more likely to be involved in violent groups. I find results more consistent with the latter stream of the literature, and then probe a bit deeper to identify a channel.

Individuals engage in reconciliation up to the point where the marginal benefit equals the marginal cost. The cost of reconciliation may be linked to the frustration endured due to the depressed labor market conditions, and therefore may be larger for highly educated individuals, explaining why highly educated individuals prefer lower levels of reconciliation.

At the macro level, it is clear that there is a strong interdependence between politics and economics, and between the socio-economic situation and attitudes towards reconciliation. While economic deprivation may not be associated with worse attitudes towards reconciliation at the individual level, periods of economic stagnation or contraction coincide with worsening attitudes at the national level. At the same time, the significantly negative effect of education on attitudes towards reconciliation strengthens. I can identify that this is not due to direct, local effects of the 
separation barrier. It hence seems plausible that events at the national level drive attitudes of people with high education. Knowing that are not personal losses what strengthes the negative attitudes towards reconciliation but rather the general situation, may be important for the peace process. Education and economic aid may not be sufficient remedies. 


\section{References}

Abadie, A. (2006), 'Poverty, Political Freedom, And The Roots Of Terrorism', American Economic Review 96(2), 50-56.

Abu Sada, M. (1998), 'Party Identification and Political Attitudes in an Emerging Democracy: A Summary.', American Journal of Political Science 42(2), 712-715.

Angrist, J. (1995), 'The Economic Returns to Schooling in the West Bank and Gaza Strip', American Economic Review 85(5), 1065-87.

Bar-Tal, D. (2000), 'From Intractable Conflict through Conflict Resolution to Reconciliation: Psychological Analysis', Political Psychology 21(2), 351-365.

Benmelech, E. and Berrebi, C. (2007), 'Human Capital and the Productivity of Suicide Bombers', Journal of Economic Perspectives 21(3), 223-238.

Berman, E. and Laitin, D. (2005), 'Hard Targets: Theory and Evidence on Suicide Attacks', NBER Working Papers (11740).

Berrebi, C. (2007), 'Evidence about the Link Between Education, Poverty and Terrorism among Palestinians', Peace Economics, Peace Science and Public Policy 13(1).

Berrebi, C. and Klor, E. (2006), 'On Terrorism and Electoral Outcomes: Theory and Evidence from the Israeli-Palestinian Conflict', Journal of Conflict Resolution 50(6), 899-925.

Berrebi, C. and Klor, E. (2007), 'Are Voters Sensitive to Terrorism? Direct Evidence from the Israeli Electorate', mimeo, Hebrew University .

Brown, N. (2001), 'Democracy, History, and the Contest over the Palestinian Curriculum', Adam Institute, Georgetown University .

Bueno de Mesquita, E. (2005), 'The Quality of Terror', American Journal of Political Science $\mathbf{9}(3), 515-530$. 
Bueno de Mesquita, E. and Dickson, E. (2007), 'The Propaganda of the Deed: Terrorism, Counterterrorism, and Mobilization', American Journal of Political Science 51(2), 364381.

Bulmer, R. (2003), 'The impact of Israeli border policy on the Palestinian labor market', Economic Development and Cultural Change 51(3), 657-676.

Douglas, J. (2001), 'Asymptotic identifiability of nonparametric item response models', Psychometrika 66(4), 531-540.

Eckstein, Z. and Tsiddon, D. (2004), 'Macroeconomic consequences of Terror: Theory and the Case of Israel', Journal of Monetary Economics 51(5), 971-1002.

Fehr, E. and Schmidt, K. (2005), The Economics of Fairness, Reciprocity and Altruism - Experimental Evidence and New Theories, in U. of Munich, ed., 'Handbook on the Economics of Giving, Reciprocity and Altruism', Serge-Christophe Kolm and Jean Mercier Ythier.

Freedman, R. O. (1979), World Politics and the Arab-Israeli Conflict, Pergamon Pr, New York.

Friedman, G. (2005), 'Commercial Pacifism and Protracted Conflict: Models from the Palestinian-Israeli Case', Journal of Conflict Resolution 49, 360-382.

Gawerc, M. (2006), 'Peace-Building: Theoretical and Concrete Perspectives', Peace and Change 31(4), 435-478.

Glaeser, E. (2002), 'The Political Economy of Hatred', NBER Working Paper (9171).

Goldin, C. and Katz, L. (2007), 'Long-Run Changes in the Wage Structure: Narrowing, Widening, Polarizing', Brookings Papers on Economic Activity (2).

Green, D., McFalls, L. and Smith, J. (2001), 'Hate Crime: An Emergent Research Agenda', Annual Review of Sociology 27, 479-504.

Hu, Y. (2008), 'Identification and estimation of nonlinear models with misclassification error using instrumental variables: A general solution', Journal of Econometrics (144), 27-61. 
Hu, Y. and Schennach, S. (2006), 'Identification and estimation of nonclassical nonlinear errorsin-variables models with continuous distributions using instruments', CeMMAP working papers (CWP17/06).

Jaeger, D., Klor, E., Miaari, S. and Paserman, D. (2008), 'The Struggle for Palestinian Hearts and Minds: Violence Public Opinion in the Second Intifada', NBER Working Paper 13956.

Jaeger, D. and Paserman, M. (2006), 'Israel, the Palestinian Factions, and the Cycle of Violence', American Economic Review 96(2), 45-49.

Jaeger, D. and Paserman, M. (2007), 'The Shape of Things to Come? Assessing the Effectiveness of Suicide Attacks and Targeted Killings', IZA Discussion Papers 2890.

Jasso, G. and Meyersson, E. (2004), 'Identity, Social Distance, and Palestinian Support for the Roadmap', Stanford University, mimeo .

Krueger, A. and Maleckova, J. (2003), 'Education, Poverty, and Terrorism: Is There a Causal Connection?', Journal of Economic Perspectives 17(4), 119-144.

Miaari, S. and Sauer, R. (2006), 'The Labor Market Costs of Conflict: Closures, Foreign Workers, and Palestinian Employment and Earnings', IZA Discussion Paper (2282).

Nachtwey, J. and Tessler, M. (2002), 'The Political Economy of Attitudes toward Peace among Palestinians and Israelis', Journal of Conflict Resolution 46(6), 260-285.

Rodriguez, G. (2008), Multilevel Generalized Linear Models, in Springer, ed., 'Handbook of Multilevel Analysis', J Leeuw and E Meijer, chapter 9.

Sayre, E. (2001a), 'Labor demand and the wage gap in the West Bank and Gaza Strip', Contemporary Economic Policy 19(2), 213-224.

Sayre, E. (2001b), 'Labor Supply, Labor Demand and the Returns to Schooling in the West Bank and Gaza Strip', The Middle East Business and Economic Review 13(1), 29-43.

Sayre, E. and Miller, K. (2004), 'Wage Compression and the Returns to Schooling for Palestinian men from 1995 to 2001', Department of Economics Agnes Scott College. 
Spady, R. (2006), 'Identification and Estimation of Latent Attitudes and their Behavioral Implications', CEMMAP Working Papers CWP12/06.

Spady, R. (2007), 'Semiparametric methods for the measurement of latent attitudes and the estimation of their behavioural consequences', CEMMAP Working Paper CWP26/07.

Steele, F. and Goldstein, H. (2007), Multilevel Models in Psychometrics, in Elsevier, ed., 'Handbook of Statistics. Pshycometrics', Vol. 26, C.R Rao and Sandip Sinharay, North-Holand, chapter 12 , pp. 401-418.

Tessler, M. and Nachtway, J. (1998), 'Islam and Attitudes toward International Conflict: Evidence from Survey Research in the Arab World', The Journal of Conflict Resolution 42(5), 619-636.

World Bank (2003), Twenty-Seven Months Intifada,Closures and Palestinian Economic Crisis: An Assessment, World Bank, Washington, DC.

World Bank (2004), Stagnation or revival : Israeli disengagement and Palestinian economic prospects, World Bank, Washington, DC.

World Bank (2005), Twenty-Seven Months Intifada,Closures and Palestinian Economic Crisis: An Assessment, World Bank, Washington, DC.

World Bank (2007), Two Years after London: Restarting Palestinian Economic Recovery, World Bank, Washington, DC.

World Bank (2008), Economic Developments and Prospects, World Bank, Washington, DC.

Zussman, A. and Zussman, N. (2006), 'Assassinations: Evaluating the Effectiveness of an Israeli Counterterrorism Policy Using Stock Market Data', Journal of Economic Perspectives 20(2), 193-206. 


\section{Appendix}

Original wording of the questions/items we use to estimate the individual's attitudes towards reconciliation:

- After reaching a peace agreement between the Palestinian side and Israel and the establishment of a Palestinian state that is recognized by Israel, the following are steps may be taken in order to enhance relations between the State of Israel and a Palestinian State. For each of the suggested steps please tell me whether you support or oppose it:

- Open borders to free movement of people and goods.

- Create joint economic institutions and ventures.

- Create joint political institutions (such as a parliament. designed eventually to lead to a confederate system)

- Take legal measures against incitement against Israel.

- Adopt school curriculum in the Palestinian state that recognizes Israel and teaches school children not to demand return of all Palestine to the Palestinians.

- After reaching a peace agreement between the Palestinian side and Israel and the establishment of a Palestinian state that is recognized by Israel, would you, under these conditions of peace, invite an Israeli colleague to visit you in your home?

Original wording of the questions/items we use to estimate the individual's attitudes towards concessions:

The individuals are informed of the permanent compromise settlement, then they are ask what do they think of each of the following items (Do they agree or disagree with them):

- Withdrawal to 1967 borders with territorial swap. (An Israeli withdrawal from all of the Gaza Strip and the evacuation of its settlements. But in the West Bank, Israel withdraws and evacuates settlements from most of it, with the exception of few settlement areas in less than $3 \%$ of the West Bank that would be exchanged with an equal amount of territory from Israel in accordance with the attached map show map. ) 
- A state without an army but with international forces. (An independent Palestinian state would be established in the areas from which Israel withdraws in the West Bank and the Gaza Strip; the Palestinian state will have no army, but it will have a strong security force but an international multinational force would be deployed to insure the safety and security of the state. Both sides will be committed to end all forms of violence directed against each other.)

- East Jerusalem as capital of the state of Palestine after it is divided. (East Jerusalem would become the capital of the Palestinian state with Arab neighborhoods coming under Palestinian sovereignty and Jewish neighborhoods coming under Israel sovereignty. The Old City (including al Haram al Sharif) would come under Palestinian sovereignty with the exception of the Jewish Quarter and the Wailing Wall that will come under Israeli sovereignty.)

- Refugees with five options for permanent residence. (With regard to the refugee question, both sides agree that the solution will be based on UN resolutions 194 and 242 and on the Arab peace initiative. The refugees will be given five choices for permanent residency. These are: the Palestinian state and the Israeli areas transferred to the Palestinian state in the territorial exchange mentioned above; no restrictions would be imposed on refugee return to these two areas. Residency in the other three areas (in host countries, third countries, and Israel) would be subject to the decision of the states in those areas. The number of refugees returning to Israel will be based on the average number of refugees admitted to third countries like Australia, Canada, Europe, and others. All refugees will be entitled to compensation for their "refugeehood" and loss of properties.)

- End the conflict. (When the permanent status agreement is fully implemented, it will mean the end of the conflict and no further claims will be made by either side. The parties will recognize Palestine and Israel as the homelands of their respective peoples.)

- A sovereign state with security arrangements. (The Palestinian state will have sovereignty over its land, water, and airspace. But Israeli will be allowed to use the Palestinian airspace for training purposes, and will maintain two early warning stations in the West Bank for 15 
years. The multinational force will remain in the Palestinian state for an indefinite period of time and its responsibility will be to insure the implementation of the agreement, and to monitor territorial borders and coast of the Palestinian state including its international border crossings.) 


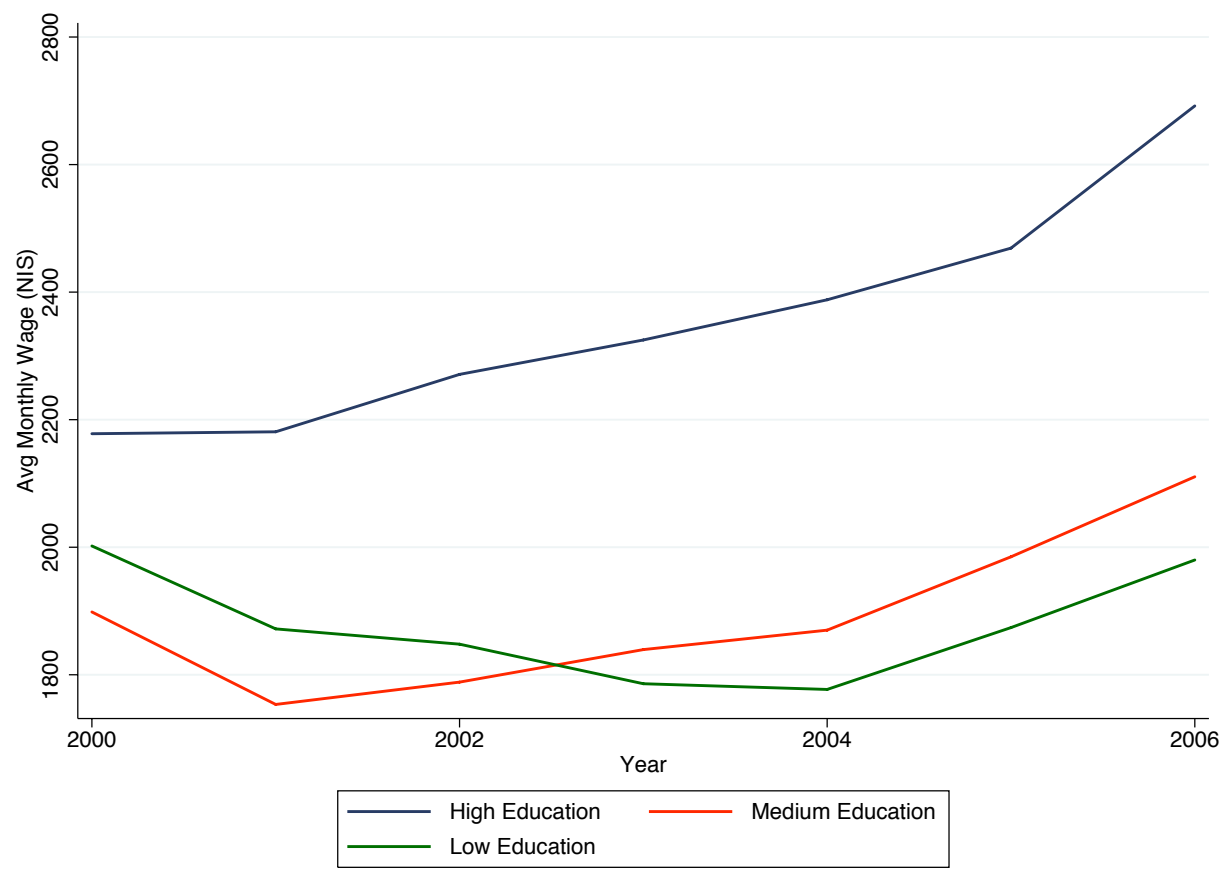

Figure 1: Average Monthly Wage in NIS for wage employees in the Palestinian Territory . Period: 2000-2006. Source: Palestinian Central Bureau of Statistics. 


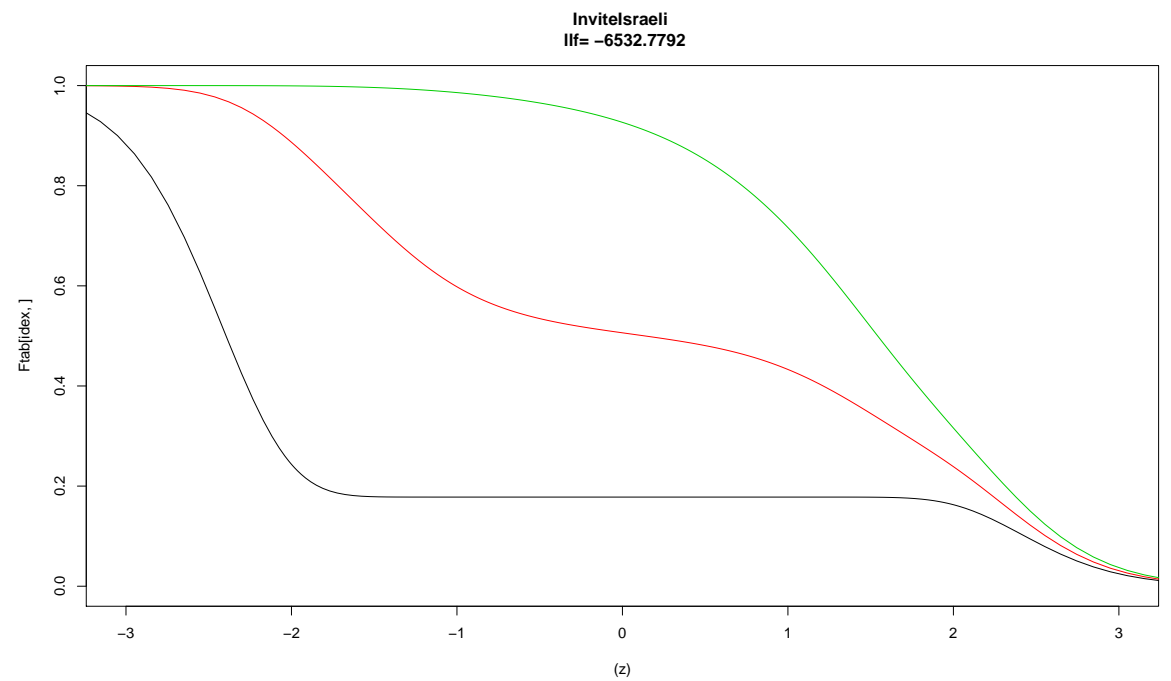

Figure 2: Probability Distributions of answering 1, 2, 3 or 4 in the item 'Invite an Israeli

Table 1: Descriptive statistics for survey questions on reconciliation and concessions

\begin{tabular}{lcc|lcc}
\hline \hline \multicolumn{3}{c}{ Reconciliation } & \multicolumn{3}{c}{ Concessions } \\
\hline Items & Mean & Std.Dev & Items & Mean & Std.Dev \\
\hline Borders & 3.038 & 0.718 & Borders 67 & 2.458 & 0.729 \\
Eco Inst. & 2.781 & 0.760 & No Army & 2.110 & 0.769 \\
Pol Inst. & 2.220 & 0.785 & Jerusalem & 2.241 & 0.790 \\
No Incitement & 2.282 & 0.776 & Refugees & 2.233 & 0.781 \\
Curriculum & 1.714 & 0.665 & End Conflict & 2.337 & 0.670 \\
Invite Israeli & 2.155 & 0.867 & Security & 2.072 & 0.867 \\
\hline Obs & \multicolumn{2}{c}{6121} & Obs & \multicolumn{2}{c}{3509} \\
Scale & $1-4$ & Scale & $1-3$ \\
\hline \hline
\end{tabular}

The survey realized in 2003 does not contain the item 'Invite an Israeli' 


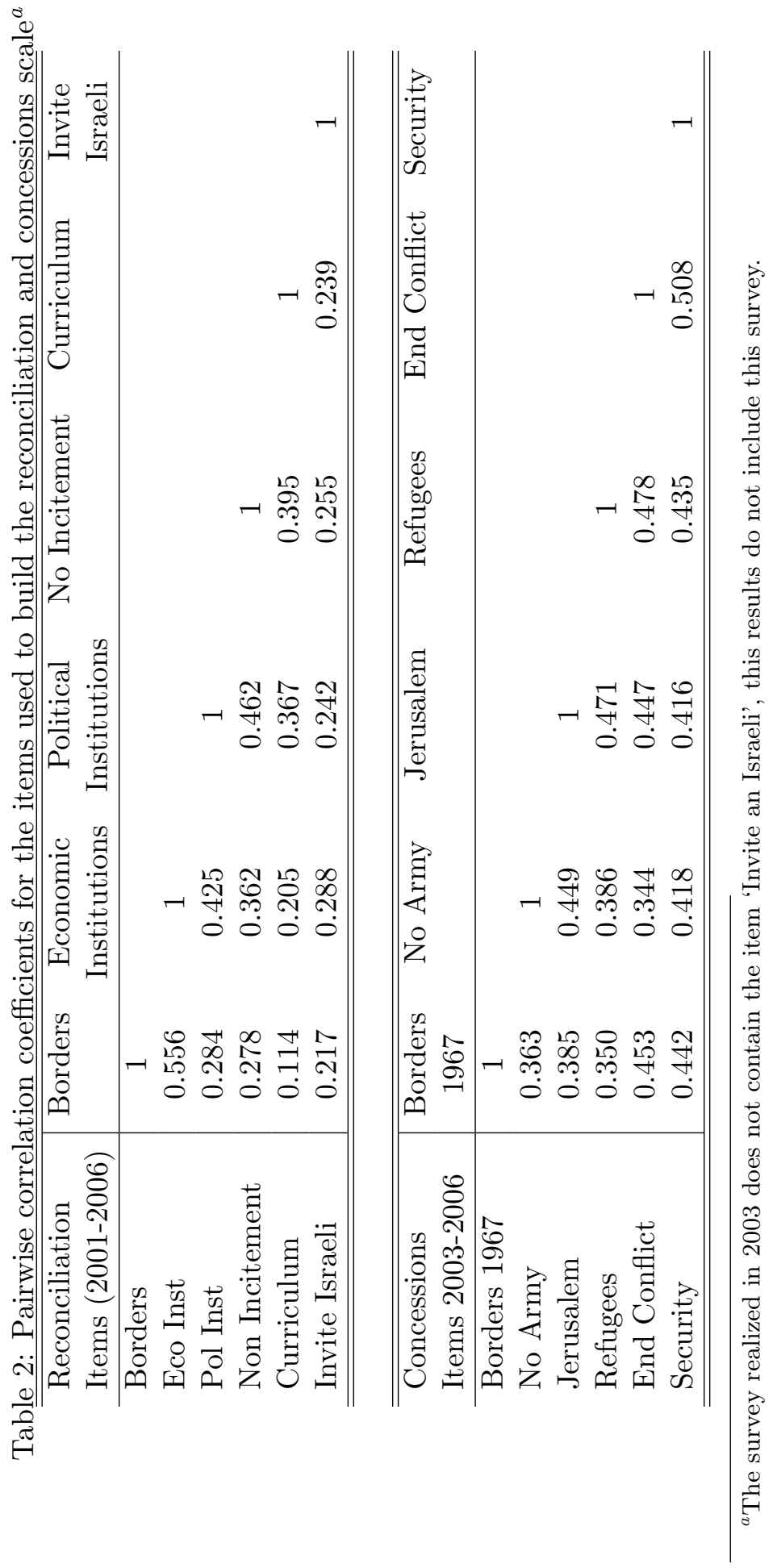




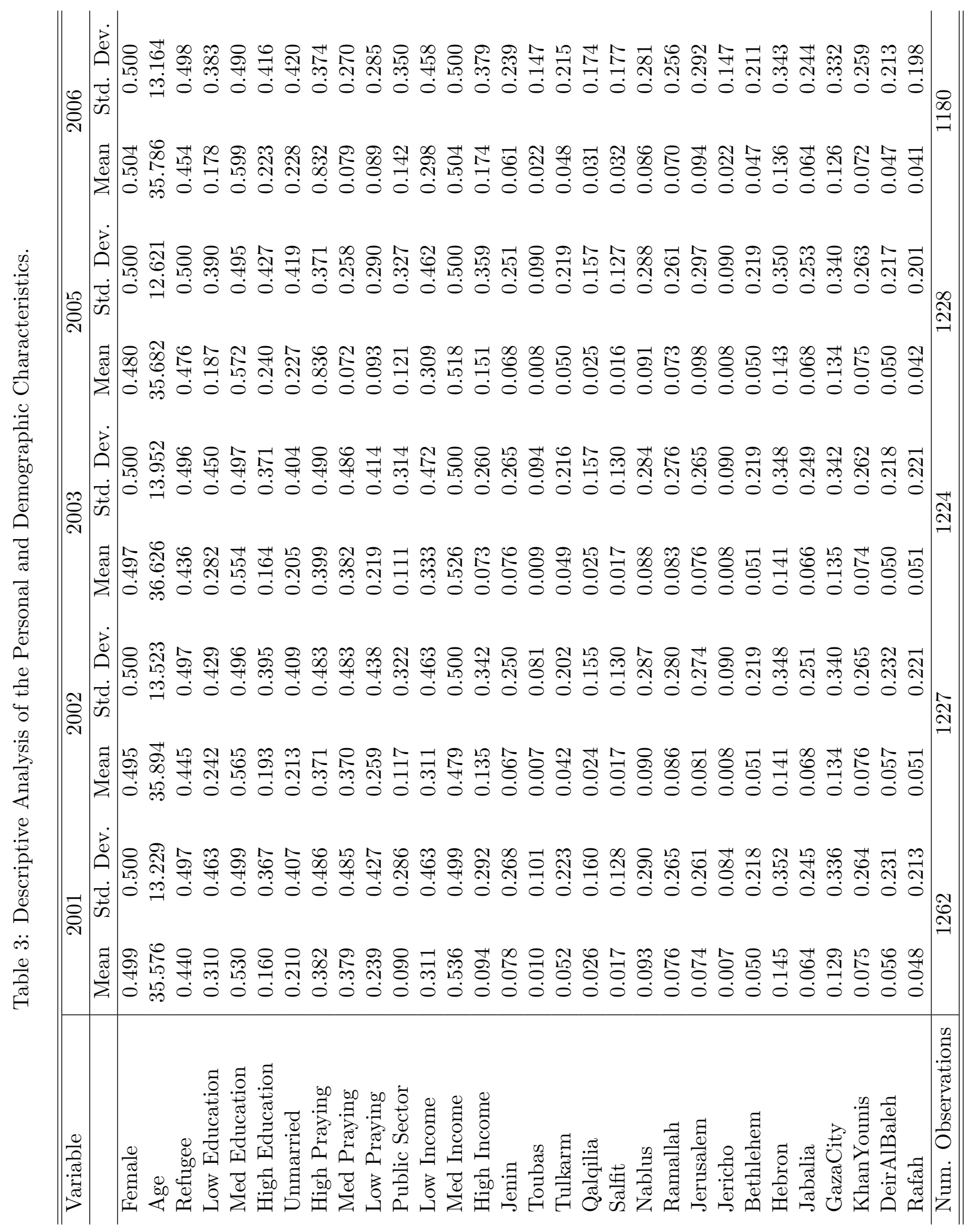




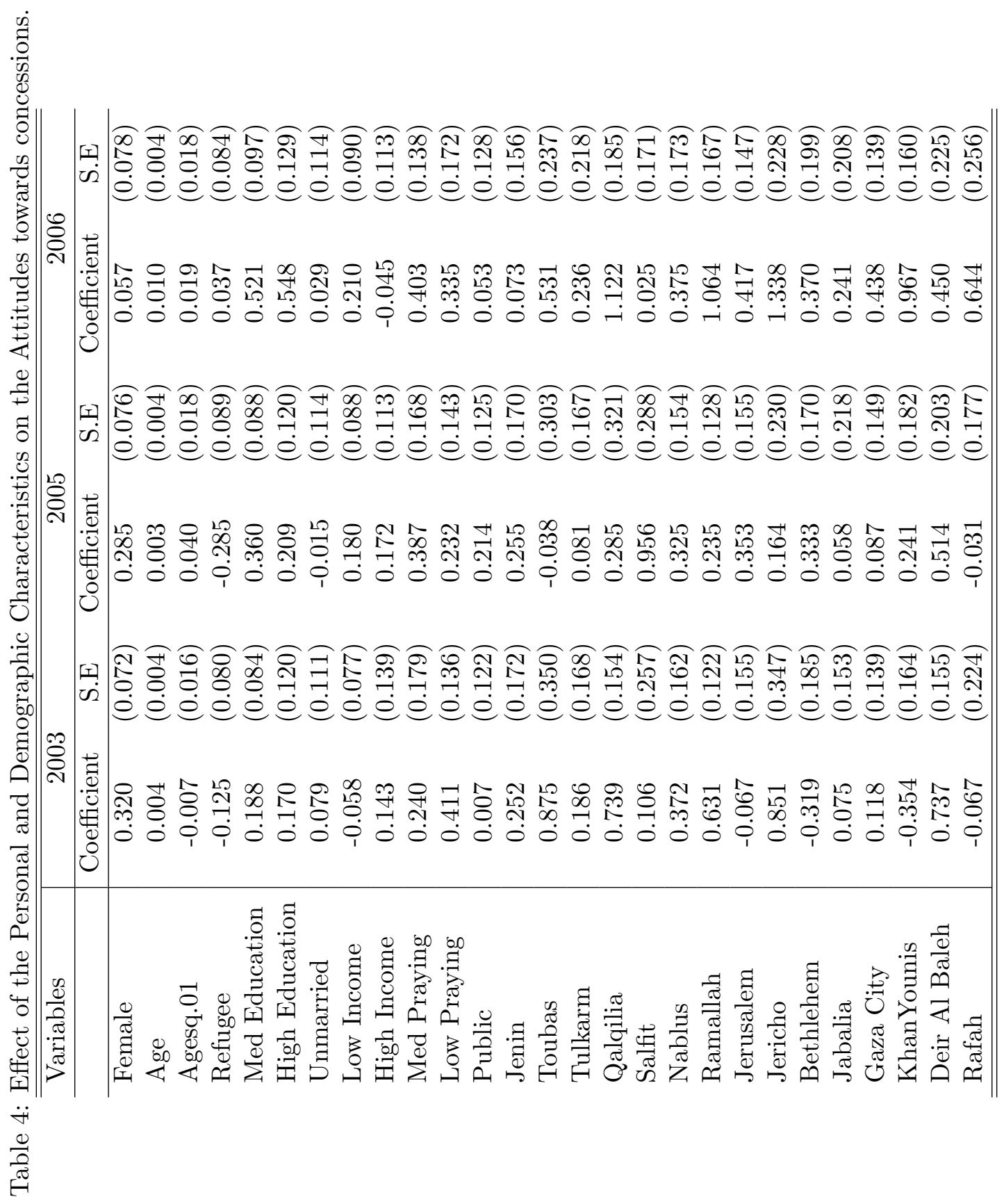




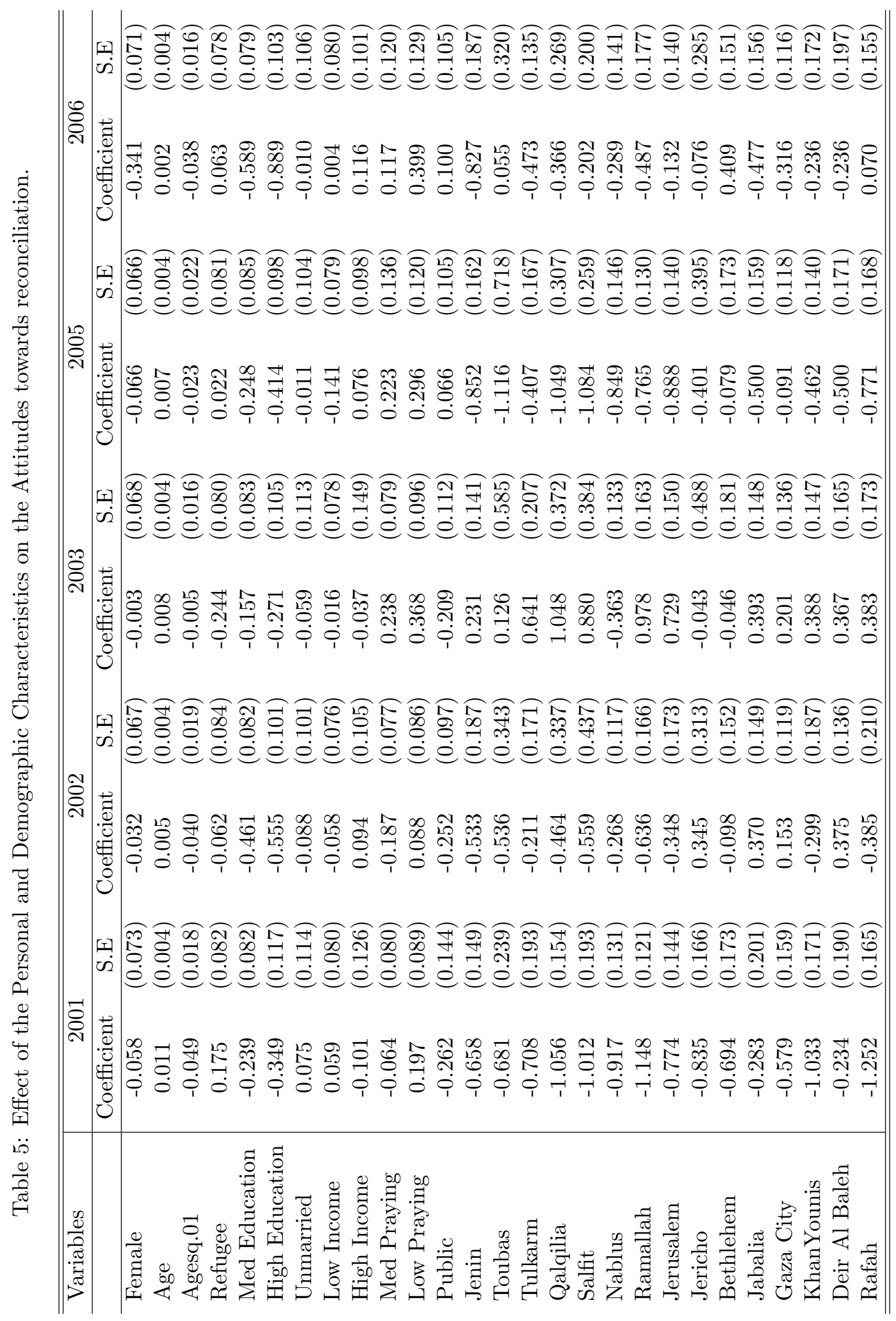


Table 6: Correlations between economic conditions and the willingness to reconcile of the educated individuals.

\begin{tabular}{lcccc}
\hline \hline & $\begin{array}{c}\text { Med Educ } \\
\text { Coefficient }\end{array}$ & $\begin{array}{c}\text { High Educ } \\
\text { Coefficient }\end{array}$ & $\begin{array}{c}\text { Med Educ } \\
\text { Coefficient }\end{array}$ & $\begin{array}{c}\text { High Educ } \\
\text { Coefficient }\end{array}$ \\
\hline per capita GDP & 0.002 & 0.002 & & \\
& $(0.001)$ & $(0.001)$ & & \\
growth rate & & & 1.370 & 1.560 \\
& & & $(0.569)$ & $(0.895)$ \\
constant & -2.625 & -3.269 & -0.303 & -0.455 \\
& $(0.795)$ & $(1.240)$ & $(0.050)$ & $(0.078)$ \\
$\mathrm{R}^{2}$ & 0.679 & 0.561 & 0.592 & 0.432 \\
observations & 6 & 6 & 6 & 6 \\
\hline \hline
\end{tabular}

Table 7: Summary of the wall and its effects in 2003, by region.

\begin{tabular}{l|ccc|cc|c}
\hline \hline & Total Area & Area Outside & Area Enclaves & Green Line & Km Wall & WE \\
& $\mathrm{Km}^{2}$ & $K m^{2}$ & $K m^{2}$ & Border $K m$ & & Index \\
\hline Jenin & 587.838 & 33.891 & 0.000 & 50.02 & 61.421 & 1.286 \\
Toubas & 352.811 & 0.000 & 0.000 & 13.092 & 0.000 & 0.000 \\
Tulkarm & 243.586 & 23.135 & 0.000 & 29.867 & 37.321 & 1.345 \\
Nablus & 615.314 & 0.000 & 0.000 & 0.000 & 0.000 & 0.000 \\
Qalqilia & 155.235 & 24.423 & 15.662 & 18.458 & 46.16 & 2.759 \\
Salfit & 211.175 & 0.000 & 0.000 & 5.598 & 4.003 & 0.715 \\
Ramallah & 849.188 & 0.000 & 0.000 & 46.283 & 0.000 & 0.000 \\
Jericho & 651.958 & 0.000 & 0.000 & 0.000 & 0.000 & 0.000 \\
Jerusalem & 345.277 & 0.000 & 0.000 & 27.375 & 15.856 & 0.579 \\
Bethlehem & 637.548 & 0.000 & 0.000 & 22.245 & 10.475 & 0.471 \\
Hebron & 1007.135 & 0.000 & 0.000 & 91.817 & 0.000 & 0.000 \\
Jabalia & 0.000 & 0.000 & 0.000 & 0.000 & 0.000 & 0.000 \\
Gaza City & 0.000 & 0.000 & 0.000 & 0.000 & 0.000 & 0.000 \\
Khan Younis & 0.000 & 0.000 & 0.000 & 0.000 & 0.000 & 0.000 \\
Deir Baleh & 0.000 & 0.000 & 0.000 & 0.000 & 0.000 & 0.000 \\
Rafah & 0.000 & 0.000 & 0.000 & 0.000 & 0.000 & 0.000 \\
\hline \hline
\end{tabular}


Table 8: Summary of the wall and its effects in 2005, by region.

\begin{tabular}{l|ccc|cc|c}
\hline \hline & Total Area & Area Outside & Area Enclaves & Green Line & Km Wall & WE \\
& $K^{2}$ & $K m^{2}$ & $K m^{2}$ & Border $K m$ & & Index \\
\hline Jenin & 587.838 & 36.104 & 0.000 & 50.02 & 65.19 & 1.365 \\
Toubas & 352.811 & 2.68 & 0.000 & 13.092 & 12.608 & 0.971 \\
Tulkarm & 243.586 & 23.135 & 0.000 & 29.867 & 37.321 & 1.345 \\
Nablus & 615.314 & 0.000 & 0.000 & 0.000 & 0.000 & 0.000 \\
Qalqilia & 155.235 & 24.423 & 15.662 & 18.458 & 56.75 & 3.333 \\
Salfit & 211.175 & 0.000 & 0.000 & 5.598 & 18.134 & 3.239 \\
Ramallah & 849.188 & 7.761 & 0.000 & 46.283 & 26.31 & 0.578 \\
Jericho & 651.958 & 0.000 & 0.000 & 0.000 & 0.000 & 0.000 \\
Jerusalem & 345.277 & 0.000 & 0.000 & 27.375 & 25.176 & 0.920 \\
Bethlehem & 637.548 & 0.000 & 0.000 & 22.245 & 10.475 & 0.471 \\
Hebron & 1007.135 & 2.325 & 0.000 & 91.817 & 14.658 & 0.162 \\
Jabalia & 0.000 & 0.000 & 0.000 & 0.000 & 0.000 & 0.000 \\
Gaza City & 0.000 & 0.000 & 0.000 & 0.000 & 0.000 & 0.000 \\
Khan Younis & 0.000 & 0.000 & 0.000 & 0.000 & 0.000 & 0.000 \\
Deir Baleh & 0.000 & 0.000 & 0.000 & 0.000 & 0.000 & 0.000 \\
Rafah & 0.000 & 0.000 & 0.000 & 0.000 & 0.000 & 0.000 \\
\hline \hline
\end{tabular}

Table 9: Summary of the wall and its effects in 2006, by region.

\begin{tabular}{l|ccc|cc|c}
\hline \hline & Total Area & Area Outside & Area Enclaves & Green Line & Km Wall & WE \\
& $\mathrm{Km}^{2}$ & $K \mathrm{~m}^{2}$ & $\mathrm{Km}^{2}$ & Border $\mathrm{Km}$ & & Index \\
\hline Jenin & 587.838 & 36.104 & 0.000 & 50.02 & 65.19 & 1.365 \\
Toubas & 352.811 & 2.68 & 0.000 & 13.092 & 12.608 & 0.971 \\
Tulkarm & 243.586 & 23.135 & 0.000 & 29.867 & 37.321 & 1.345 \\
Nablus & 615.314 & 0.000 & 0.000 & 0.000 & 0.000 & 0.000 \\
Qalqilia & 155.235 & 37.318 & 15.662 & 18.458 & 56.75 & 3.416 \\
Salfit & 211.175 & 13.567 & 0.000 & 5.598 & 25.86 & 4.684 \\
Ramallah & 849.188 & 84.521 & 1.512 & 46.283 & 59.158 & 1.379 \\
Jericho & 651.958 & 0.000 & 0.000 & 0.000 & 0.000 & 0.000 \\
Jerusalem & 345.277 & 93.466 & 13.883 & 27.375 & 80.724 & 3.260 \\
Bethlehem & 637.548 & 8.815 & 0.000 & 22.245 & 10.475 & 0.485 \\
Hebron & 1007.135 & 12.71 & 0.000 & 91.817 & 64.757 & 0.718 \\
Jabalia & 0.000 & 0.000 & 0.000 & 0.000 & 0.000 & 0.000 \\
Gaza City & 0.000 & 0.000 & 0.000 & 0.000 & 0.000 & 0.000 \\
Khan Younis & 0.000 & 0.000 & 0.000 & 0.000 & 0.000 & 0.000 \\
Deir Baleh & 0.000 & 0.000 & 0.000 & 0.000 & 0.000 & 0.000 \\
Rafah & 0.000 & 0.000 & 0.000 & 0.000 & 0.000 & 0.000 \\
\hline \hline
\end{tabular}




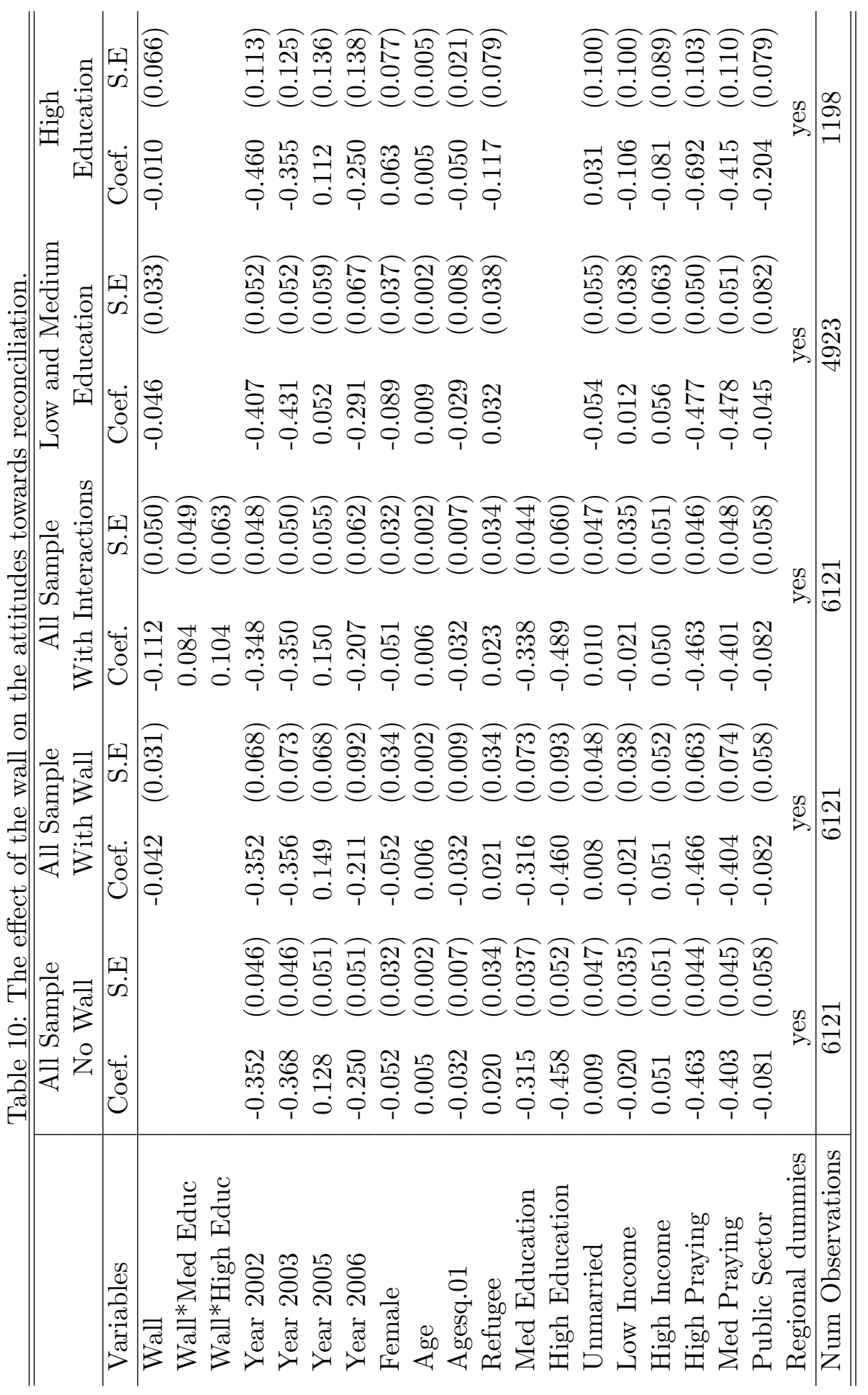




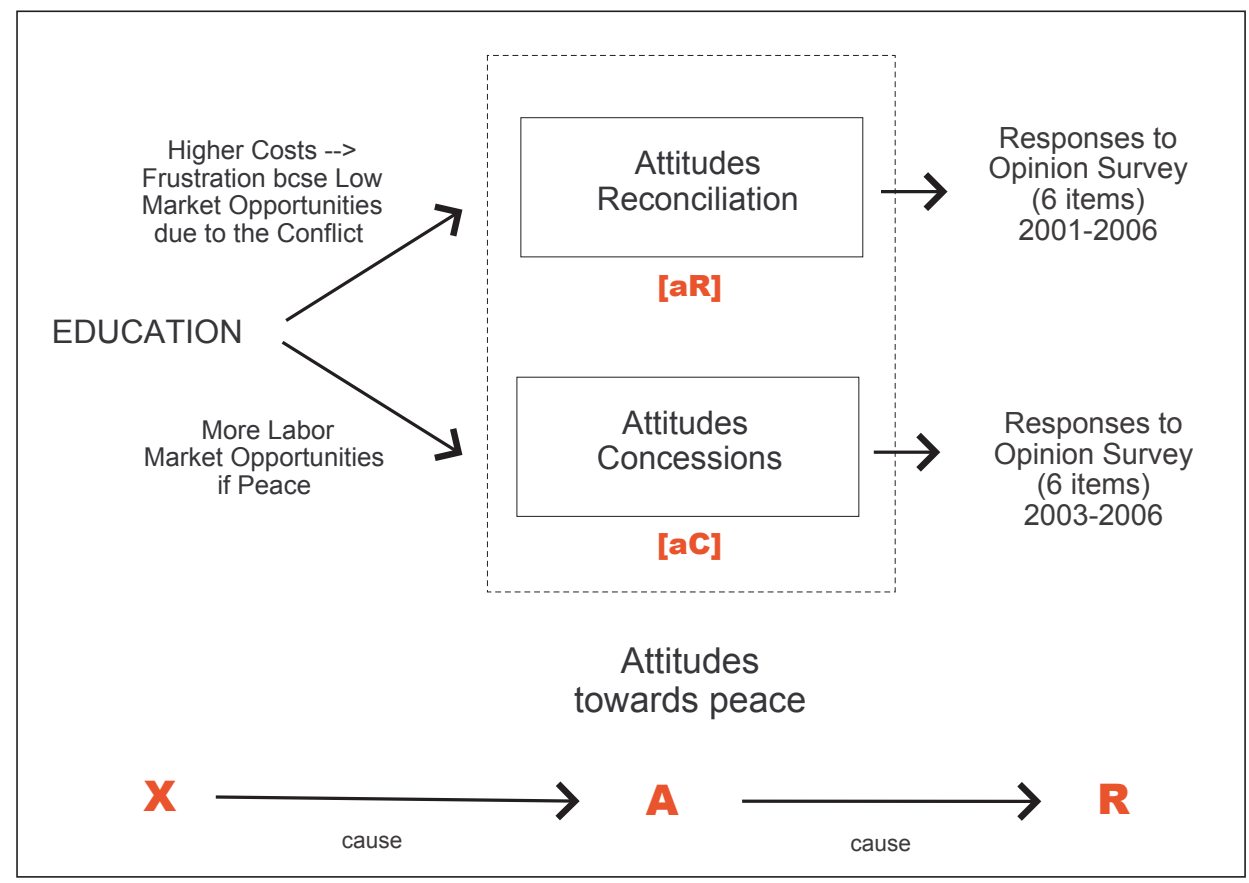

Figure 3: Diagram of the underlying process. 


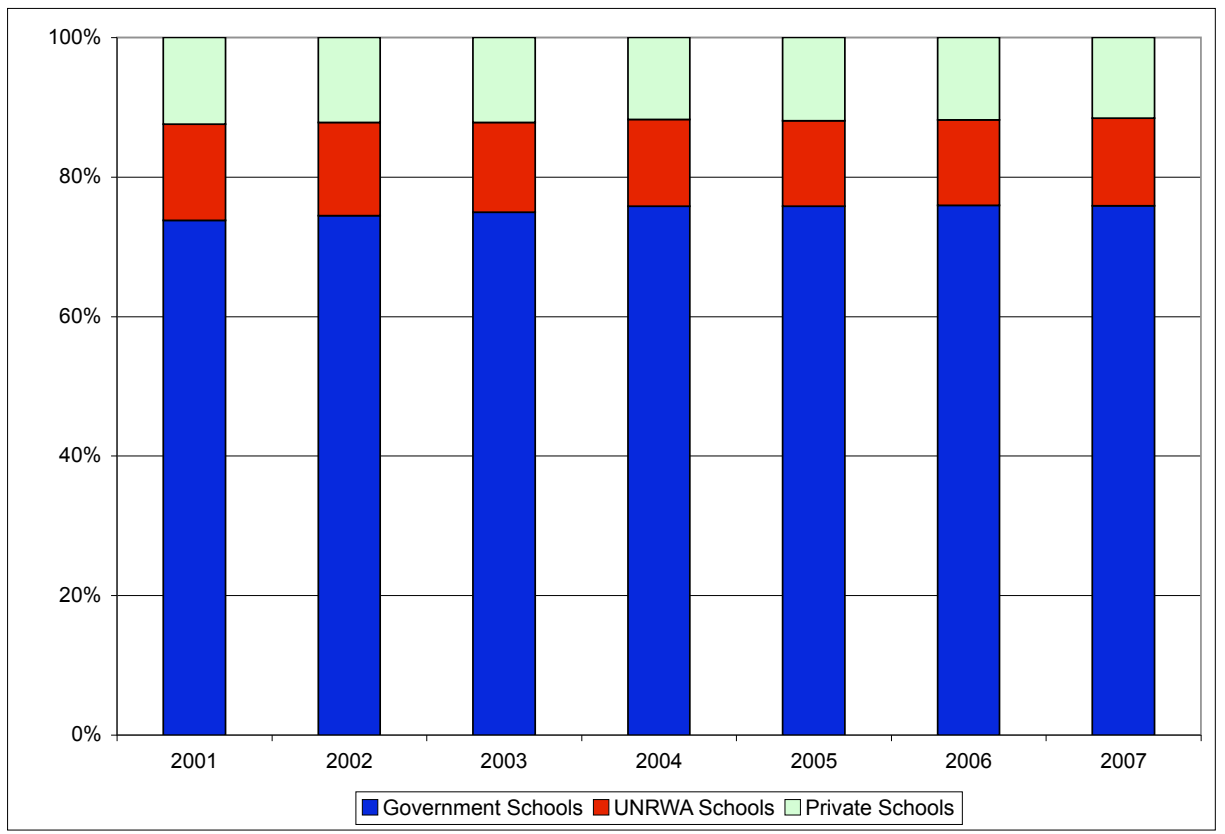

Figure 4: Distribution of the schools by supervising authority. Source: Palestinian Education Ministry. 


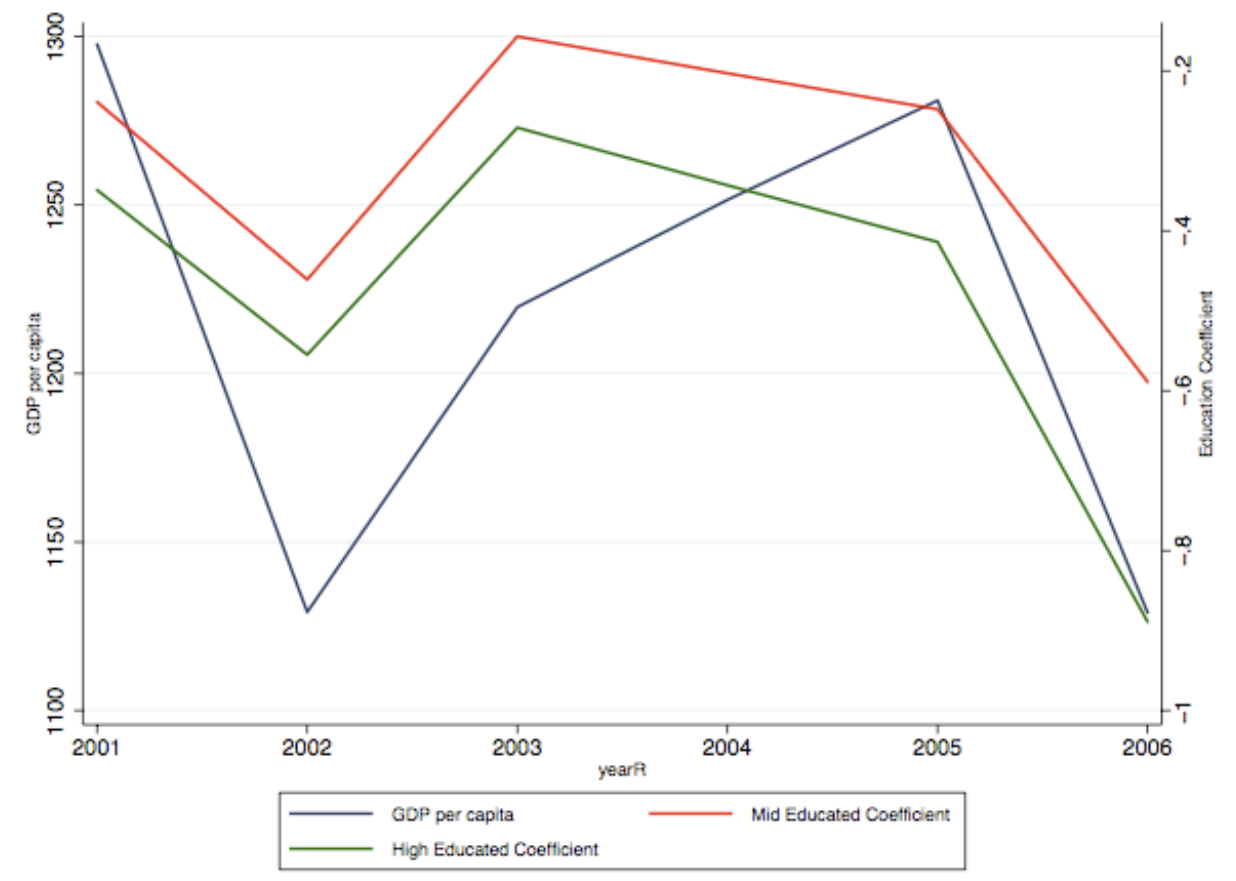

Figure 5: Coefficients associated to the education variables and evolution of GDP per capita. 

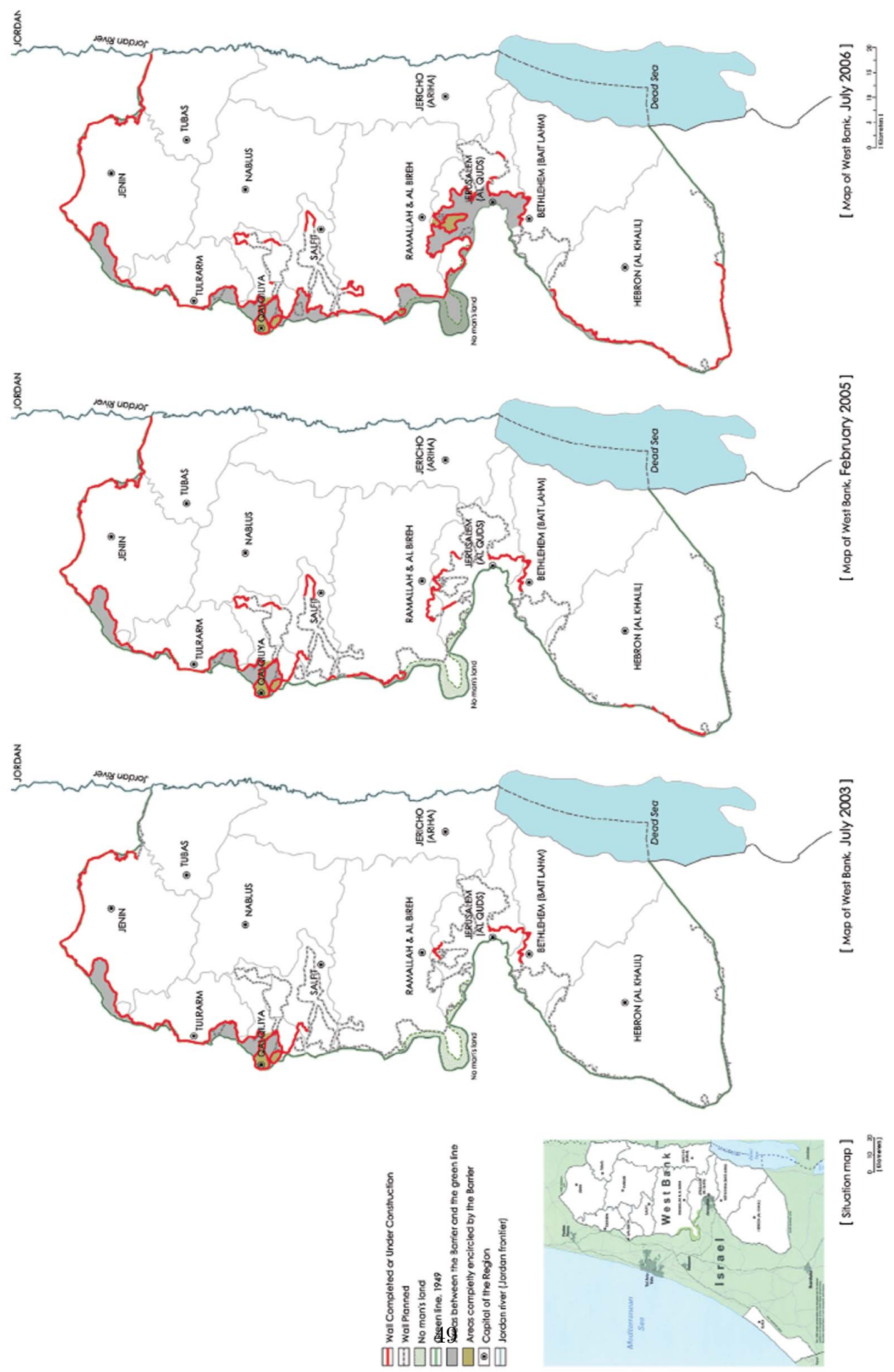

Figure 6: Evolution of the Separation Barrier. 

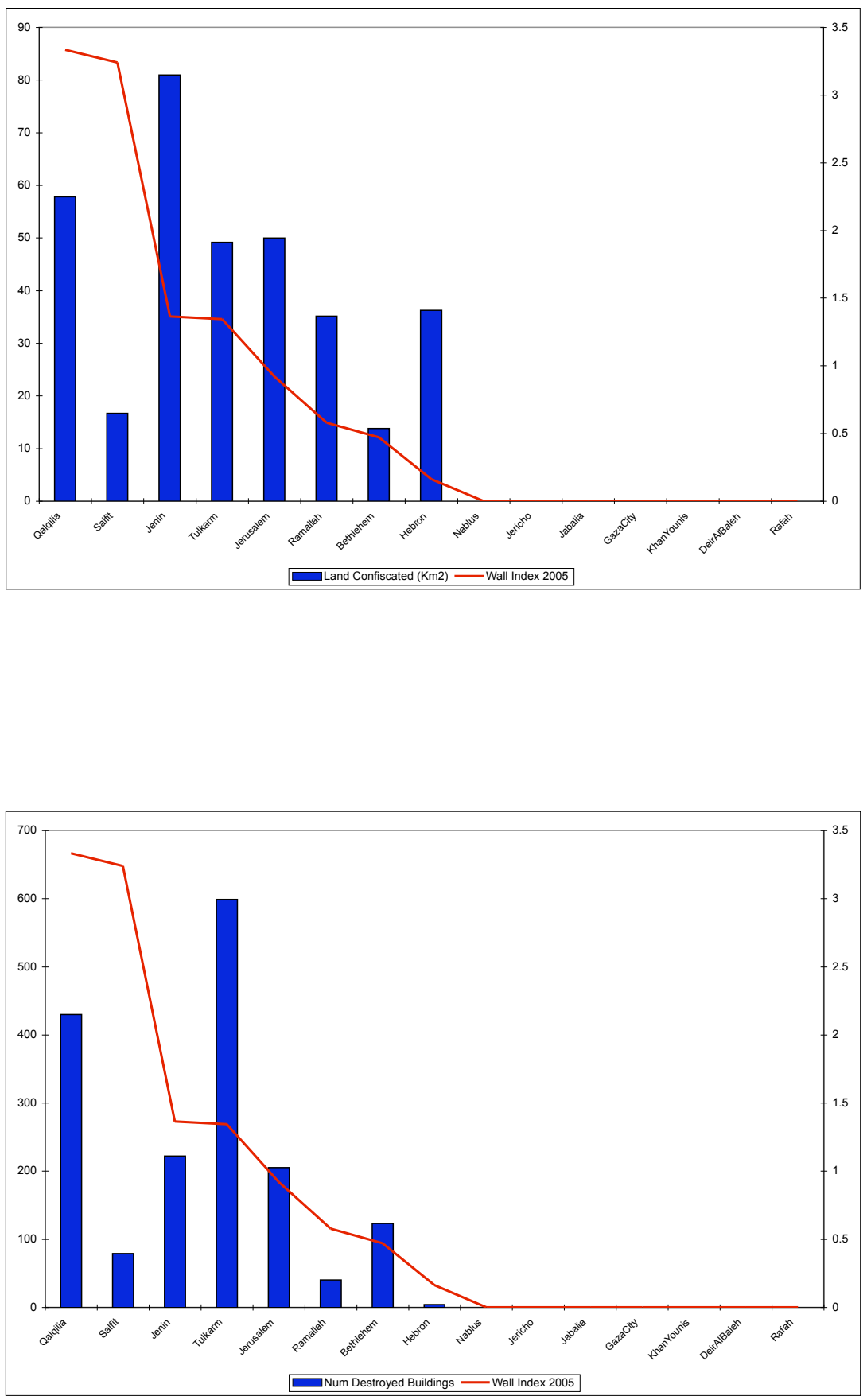

Figure 7: Correlation between the index used and other possible measures of the effect of the wall. The number of buildings destroyed refer to the number of establishments in different sectors which were totally closed as a result of $\mathrm{l}_{\text {he }}$ wall, the confiscated land is the total area confiscated by Israeli forces to construct the wall (usually taken by military order). Source: PCBS - Survey on the Impact of the Expansion and Annexation Wall on the Socio-Economic Conditions of Palestinian Localities which the Wall Passes Through, June 2005. 